\title{
AVTA Federal Fleet PEV Readiness Data Logging and Characterization Study: Final Report
}

Stephen Schey

Jim Francfort

June 2015

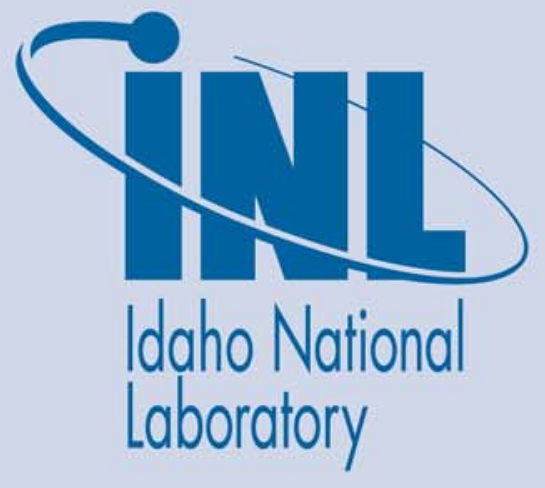

The INL is a U.S. Department of Energy National Laboratory operated by Battelle Energy Alliance 


\section{DISCLAIMER}

This information was prepared as an account of work sponsored by an agency of the U.S. Government. Neither the U.S. Government nor any agency thereof, nor any of their employees, makes any warranty, expressed or implied, or assumes any legal liability or responsibility for the accuracy, completeness, or usefulness, of any information, apparatus, product, or process disclosed, or represents that its use would not infringe privately owned rights. References herein to any specific commercial product, process, or service by trade name, trade mark, manufacturer, or otherwise, does not necessarily constitute or imply its endorsement, recommendation, or favoring by the U.S. Government or any agency thereof. The views and opinions of authors expressed herein do not necessarily state or reflect those of the U.S. Government or any agency thereof. 
INL/EXT-15-35799

\title{
AVTA Federal Fleet PEV Readiness Data Logging and Characterization Study: Final Report
}

\author{
Stephen Schey \\ Jim Francfort ${ }^{2}$
${ }^{1}$ Stephen Schey, Project Manager, Infrastructure Planning and Analysis, Intertek Testing Services, North America, Phoenix, Arizona
${ }^{2}$ Jim Francfort, Vehicle Systems Principal Investigator, Idaho National Laboratory, operated by Battelle Energy Alliance, Idaho Falls, Idaho

June 2015

\author{
Idaho National Laboratory \\ Idaho Falls, Idaho 83415
}

http://avt.inl.gov

Prepared for the

U.S. Department of Energy

Office of Nuclear Energy

Under DOE Idaho Operations Office

Contract DE-AC07-05ID14517 


\section{ABSTRACT}

Battelle Energy Alliance, LLC, managing and operating contractor for the U.S. Department of Energy's Idaho National Laboratory, is the lead laboratory for the U.S. Department of Energy's advanced vehicle testing. Battelle Energy Alliance, LLC contracted with Intertek Testing Services, North America (Intertek) to support the collection and evaluation of data on federal fleet operations as part of the Advanced Vehicle Testing Activity's Federal Fleet Vehicle Data Logging and Characterization Study. The Advanced Vehicle Testing Activity study seeks to collect and evaluate data to validate utilization of advanced plug-in electric vehicle (PEV) transportation.

This report summarizes the fleets studied to identify the daily operational characteristics of select vehicles and report findings on vehicle and mission characterizations to support successful introduction of PEVs into the agencies' fleets.

Individual observations of these selected vehicles provide the basis for recommendations related to electric vehicle adoption and whether a battery electric vehicle or plug-in hybrid electric vehicle (collectively referred to as PEVs) can fulfill the mission requirements. 


\section{EXECUTIVE SUMMARY}

Federal agencies are mandated to purchase alternative fuel vehicles, increase consumption of alternative fuels, and reduce petroleum consumption. Available plug-in electric vehicles (PEVs) provide an attractive option in the selection of alternative fuel vehicles. PEVs, which consist of both battery electric vehicles (BEVs) and plug-in hybrid electric vehicles (PHEVs), have significant advantages over internal combustion engine (ICE) vehicles in terms of energy efficiency, reduced petroleum consumption, and reduced production of greenhouse gas (GHG) emissions and performance benefits with quieter, smoother operation. This study intended to evaluate the extent that selected federal agencies could convert part or all of their fleet of vehicles from petroleum-fueled vehicles to PEVs and to generalize that information to be of use to all agencies.

The study for each participating agency began with selection of a subset of vehicles closely representative of their inventory for specific data logging and monitoring. The data analysis provided information that supported recommendations relating to adoption of PEVs into that agency's fleet. A report was issued to each agency and posted to the Idaho National Laboratory website. This paper provides a summary report.

More fuel-efficient ICE vehicles, including hybrid electric vehicles, exist that may provide improvements for the current fleet; however, this study's focus is on replacing ICE vehicles with suitable PEVs.

BEVs provide the greatest benefit when it comes to fuel and emissions savings because all motive power is provided by the energy stored in the onboard battery pack. These vehicles use no petroleum and emit no pollutants at their point of use. PHEVs provide similar savings when their battery provides all or a majority of the motive power (depending on PHEV design); however, they also have the ability to extend their operating range with an onboard ICE. Because a PHEV can meet all transportation range needs, the adoption of a PHEV will be dependent on its ability to meet other transportation needs such as passenger or cargo requirements. Operation of PHEVs in charge-depleting mode, where all or a majority of the motive power is provided by the battery, can be increased with opportunity charging at available charging stations. This study focuses on mission requirements of the fleet vehicles, with an objective of identifying vehicles that may be replaced with PEVs, with emphasis on BEVs that provide maximum benefit.

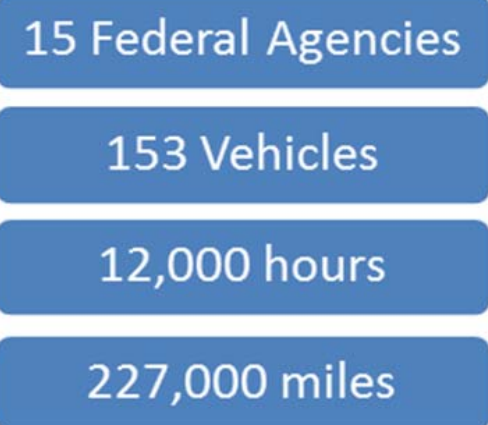

Fifteen federal agencies participated in this study, providing fleet information, assistance in selection of the total 153 vehicles for monitoring, and installation, and removal of data loggers. The published reports for each agency observe that a mix of BEVs and PHEVs are capable of performing most of the required missions and providing alternative vehicles for the pool, support, and enforcement vehicles. While some vehicles travel long distances, these groups could support some BEVs for the short trips and PHEVs for the longer trips. Replacement of vehicles in the current fleet would result in significant reductions 
in the emission of GHGs and in petroleum use, as well as reduced fleet operating costs.

The study collected over 227,000 miles of data on 153 vehicles, which were in operation over 12,000 hours. Of these vehicles, 149 replacement PEVs appear

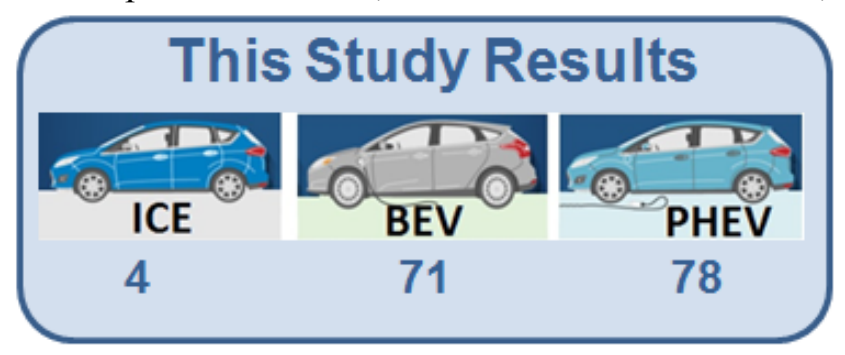
to be able to conduct the same mission and usage requirements. With emphasis on use of BEVs, 71 BEVs and 78 PHEVs were suggested as replacements.

PEVs currently commercially available cannot replace certain vehicles and missions, such as those requiring heavy-duty, load-hauling trucks, and specialty needs. However, based on data collected for the monitored vehicles, replacement of these 149 ICE vehicles with PEVs could potentially result in an annual GHG savings over $368,000 \mathrm{lb}-\mathrm{CO}_{2} \mathrm{e}(40 \%$ reduction) and an annual fuel cost savings of over $\$ 116,300$ (75\% reduction). PEV replacement projects a savings per vehicle of approximately $\$ 780$ per year in fuel costs and reduces GHG emissions by more than 1 ton each year.

Based on data collected from the monitored vehicles and extrapolating to the appropriate fleets of vehicles, replacement of the 1,454 ICE vehicles with PEVs potentially results in an annual GHG savings over 4,843,000 lb- $\mathrm{CO}_{2} \mathrm{e}$ (44\% reduction) and an annual fuel cost savings of over $\$ 1,229,000$ ( $76 \%$ reduction).

\section{PEV Replacements}

\section{$368,000 \mathrm{lb}-\mathrm{CO}_{2} \mathrm{e}$ avoided}

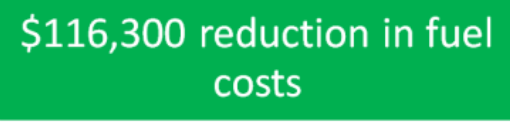

Agencies determine their vehicle

\section{1,454 PEV Replacements}

\section{4,843,000 lb- $\mathrm{CO}_{2} \mathrm{e}$ avoided}

\section{$\$ 1,229,000$ reduction in}

fuel costs needs based on the mission they are required to perform. Fleet vehicle mission categories are defined in Section 4. While the agencies' vehicles conduct many different missions, four (i.e., pool, support, enforcement, and transport missions) were selected by agencies' management and INL to be part of this fleet evaluation.

Data show that analysis of vehicles by mission type is effective in identifying potential PEV replacements for ICE vehicles and can provide guidance to fleet managers on vehicle acquisition.

It is suggested that the agencies may wish to move forward in the near future with replacement of pool, support, and enforcement vehicles with PEVs as current budget and vehicle replacement schedules allow. Certainly, the vehicle types studied in these reports may be candidates for immediate replacement. Data show composition of fleets with percentages shown in the following figure is conservative. 
This work was supported by the Federal Energy Management Program, and Vehicle Technologies Office, both located within the Department of Energy's Office of Energy Efficiency and Renewable Energy. The authors are hopeful that the reports provided to the agencies are helpful for incorporation of PEVs into their fleets.

\begin{tabular}{|c|cc|}
\hline Mission & BEVs & PHEVs \\
\hline Pool & $26 \%$ & $74 \%$ \\
\hline Support & $41 \%$ & $59 \%$ \\
\hline Enforcement & $23 \%$ & $77 \%$ \\
\hline
\end{tabular}




\section{TABLE OF CONTENTS}

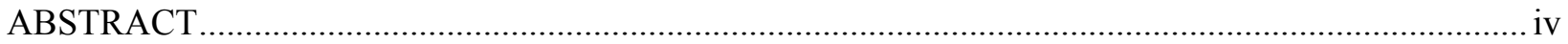

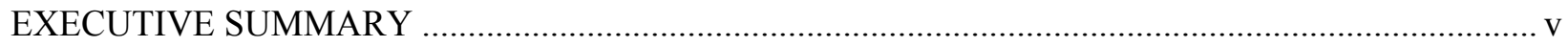

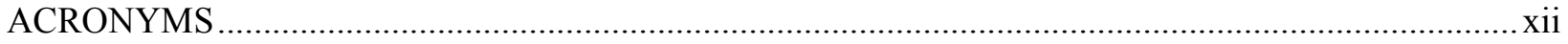

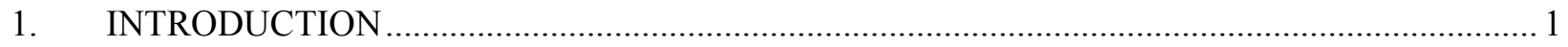

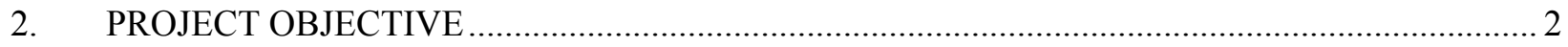

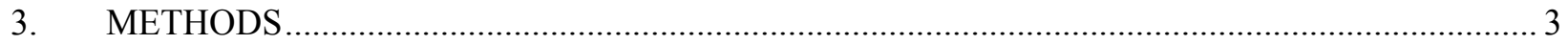

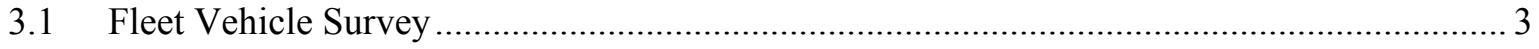

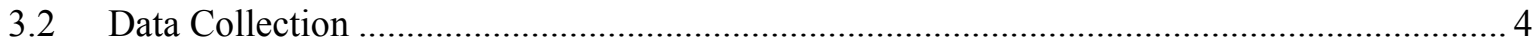

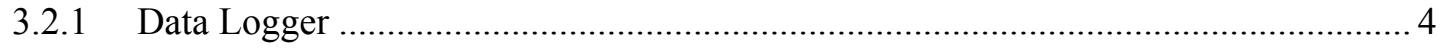

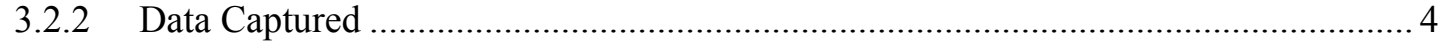

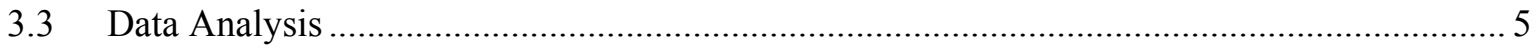

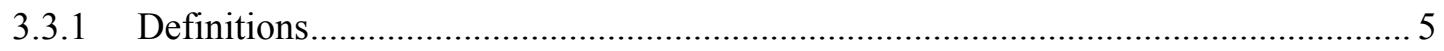

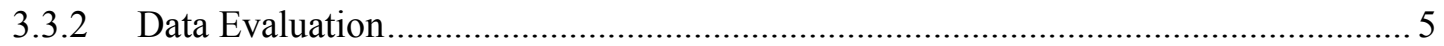

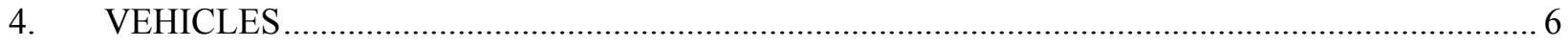

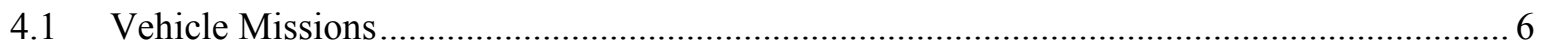

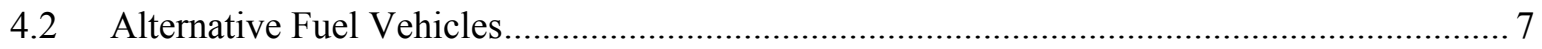

4.3 Battery Electric Vehicle and Plug-in Hybrid Electric Vehicle Benefits and

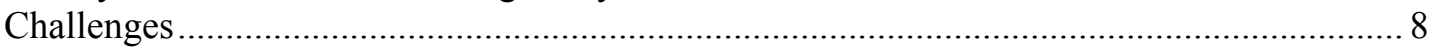

4.3.1 Battery Electric Vehicle Benefits/Challenges ..................................................... 8

4.3.2 Plug-in Hybrid Electric Vehicle Benefits/Challenges................................................. 8

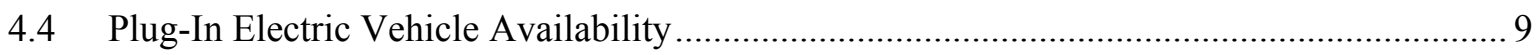

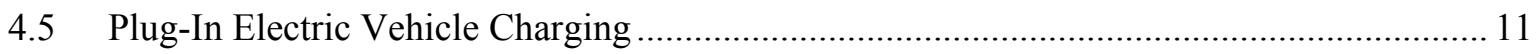

4.5.1 Electric Vehicle Supply Equipment Design......................................................... 11

4.5.2 Electric Vehicle Supply Equipment Stations ...................................................... 15

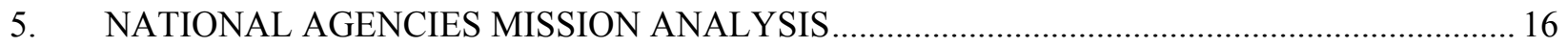

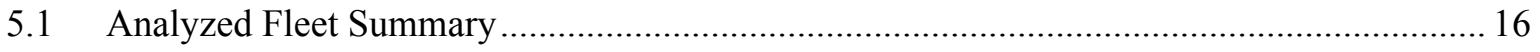

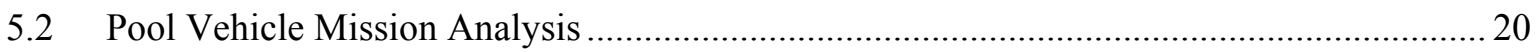

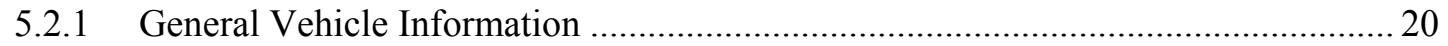




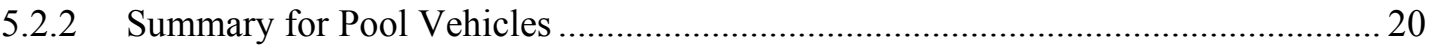

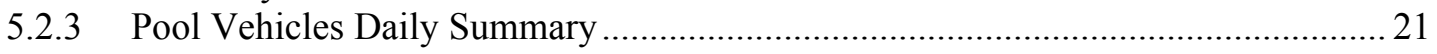

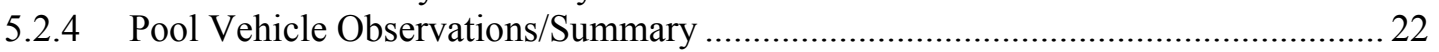

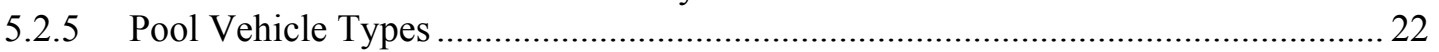

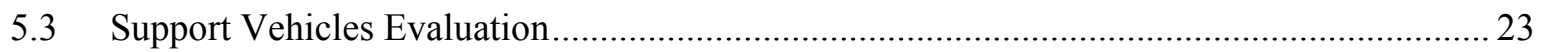

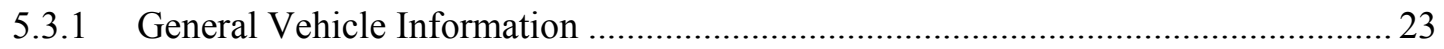

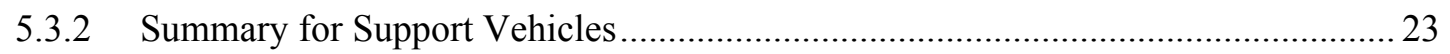

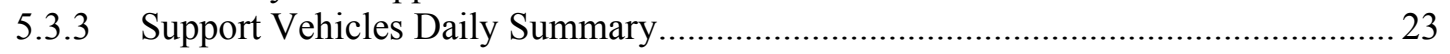

5.3.4 Support Vehicle Observations/Summary ............................................................ 24

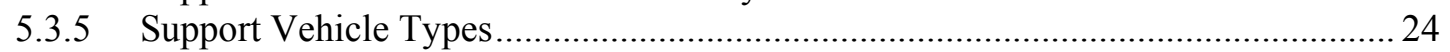

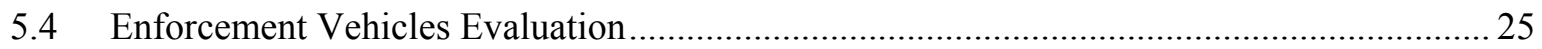

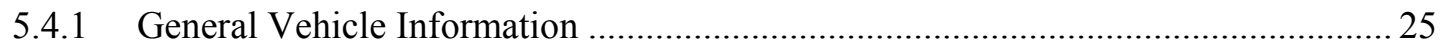

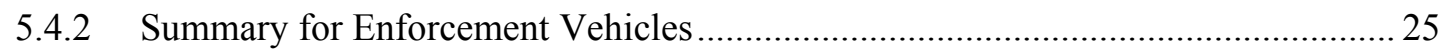

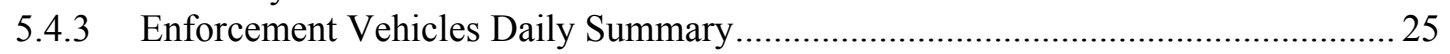

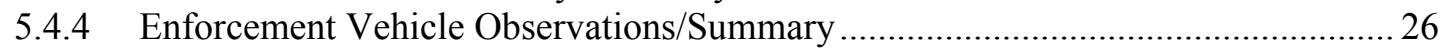

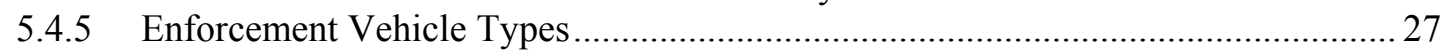

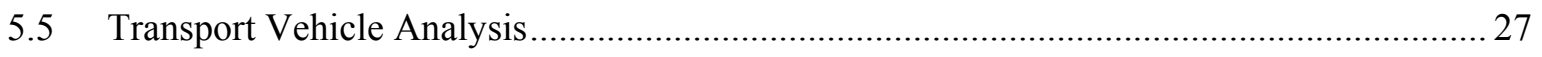

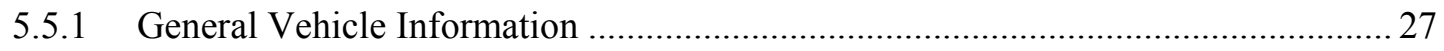

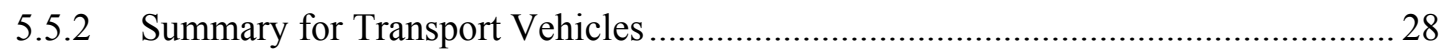

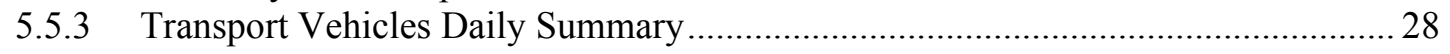

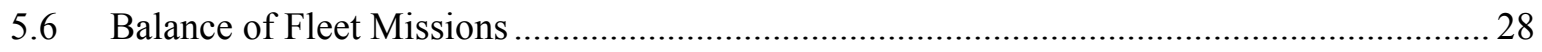

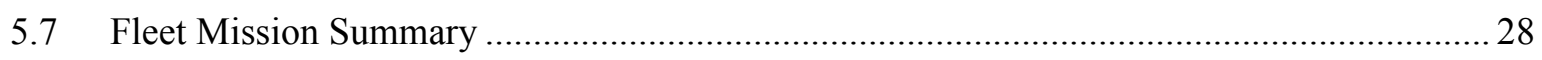

6. GREENHOUSE GAS EMISSIONS AVOIDED AND FUEL COST REDUCTION

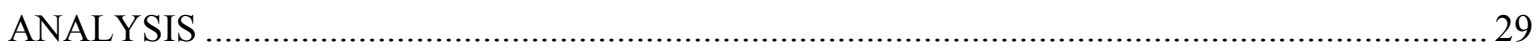

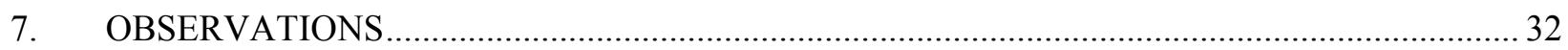

\section{FIGURES}

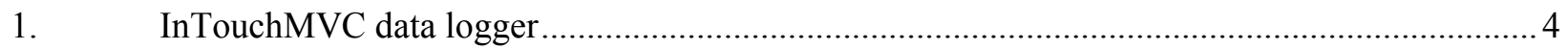

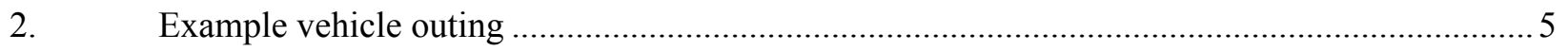

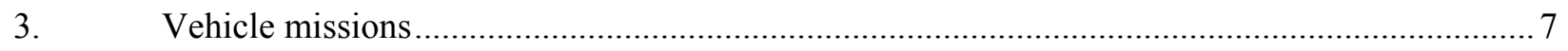

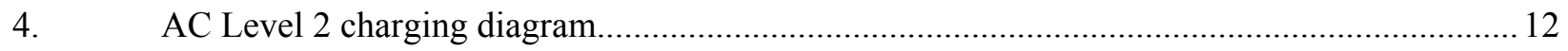

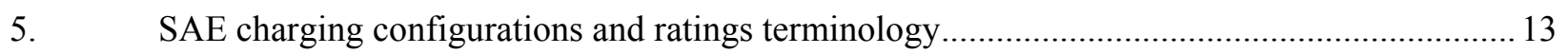

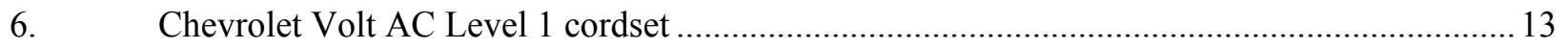




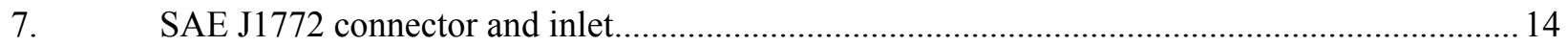

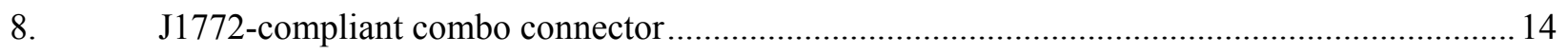

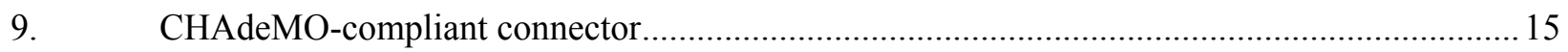

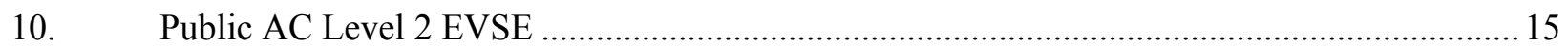

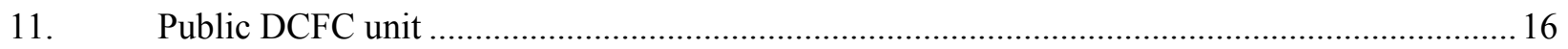

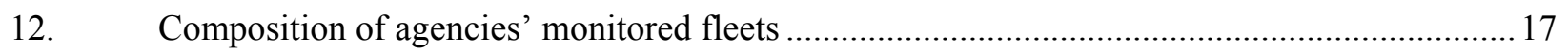

13. Comparison of monitored vehicles types versus full fleet vehicle types ................................ 17

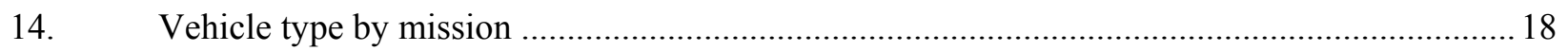

15. Mission comparison of monitored vehicles to the full fleet of vehicles ..................................... 19

16. Average and maximum daily travel for monitored vehicles.................................................. 19

17. Average and maximum outings for monitored vehicles ......................................................20

18. Pool vehicle average and maximum daily travel miles (all vehicles) ....................................2

19. Pool vehicle average and maximum outing travel miles (all vehicles) .................................2

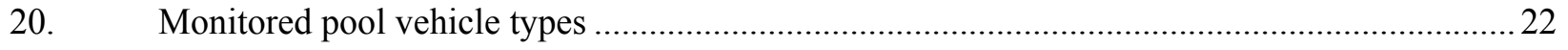

21. Support vehicle average and maximum daily travel miles (all vehicles) ..............................23

22. Support vehicle average and maximum daily outing miles (all vehicles)..............................24

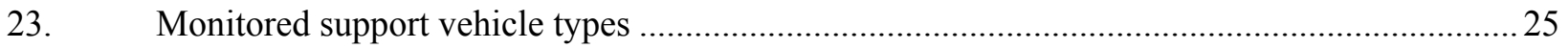

24. Enforcement vehicle average and maximum daily travel miles (all vehicles) ........................26

25 .Enforcement vehicle average and maximum daily outing miles (all vehicles) ......................26

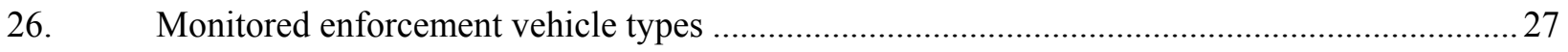

\section{TABLES}

1. Agencies and vehicles for the Advanced Vehicle Testing Activity Federal Fleet Vehicle

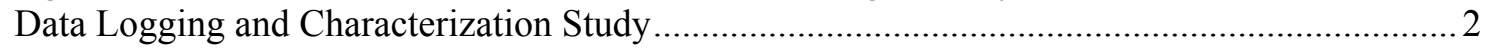

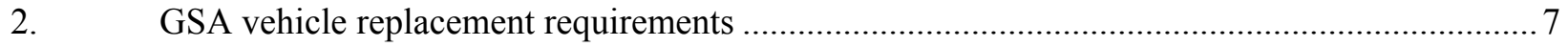

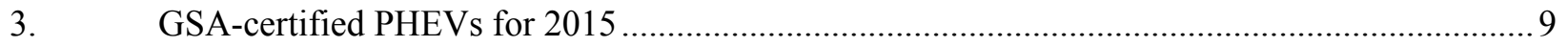

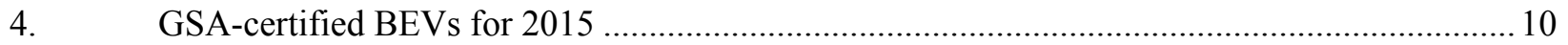




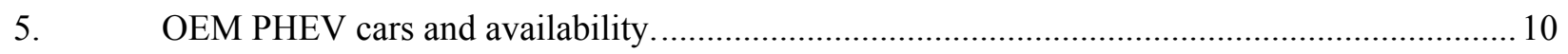

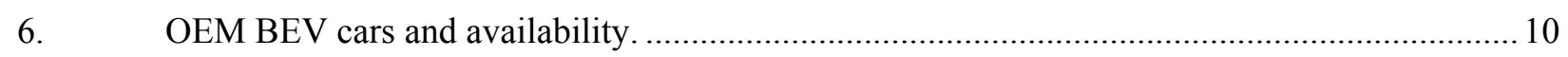

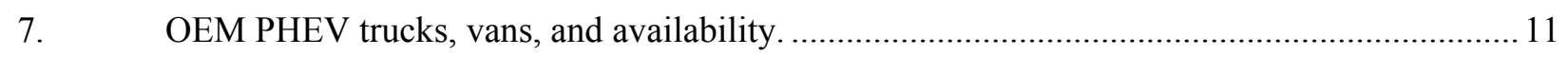

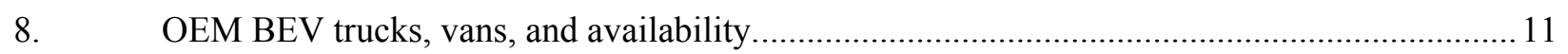

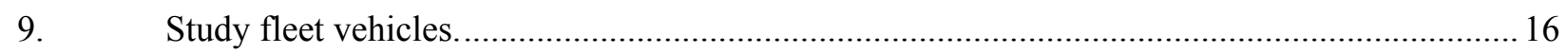

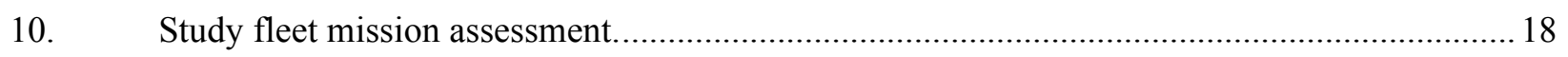

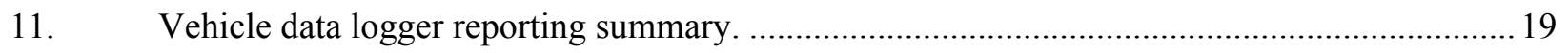

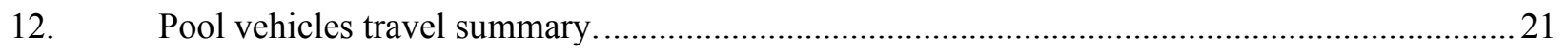

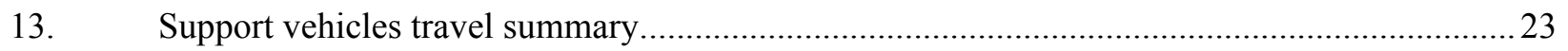

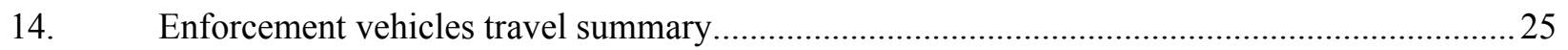

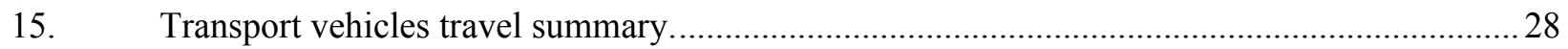

16. All mission vehicle summary of possible PEV replacement.................................................28

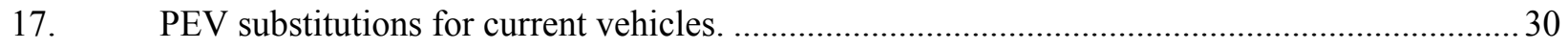

18. GHG emissions avoidance and fuel cost reduction for monitored vehicles. .............................31

19. Extrapolated GHG emissions avoided and fuel cost savings for the entire fleets. .................... 32 


\section{ACRONYMS}

$\begin{array}{ll}\text { AC } & \text { alternating current } \\ \text { BEV } & \text { battery electric vehicle } \\ \text { CD } & \text { charge depleting } \\ \text { CS } & \text { charge sustaining } \\ \text { DC } & \text { direct current } \\ \text { DCFC } & \text { DC fast charger } \\ \text { EPA } & \text { Environmental Protection Agency } \\ \text { EVSE } & \text { electric vehicle supply equipment } \\ \text { GHG } & \text { greenhouse gas } \\ \text { GSA } & \text { General Services Administration } \\ \text { ICE } & \text { internal combustion engine } \\ \text { INL } & \text { Idaho National Laboratory } \\ \text { Intertek } & \text { Intertek Testing Services, North America } \\ \text { OEM } & \text { original equipment manufacturer } \\ \text { PEV } & \text { plug-in electric vehicle } \\ \text { PHEV } & \text { plug-in hybrid electric vehicle } \\ \text { SAE } & \text { Society of Automotive Engineers } \\ \text { SUV } & \text { sports utility vehicle }\end{array}$




\section{AVTA Federal Fleet PEV Readiness Data Logging and Characterization Study: Final Report}

\section{INTRODUCTION}

Federal agencies are mandated by the Energy Policy Act of 1992, ${ }^{1}$ Energy Policy Act of 2005, ${ }^{2}$ Executive Order 13423 (President Bush, 2007), ${ }^{3}$ Executive Order 13514 (President Obama, 2009), ${ }^{4}$ and the Energy Independence and Security Act of $2007^{5}$ to purchase alternative fuel vehicles, increase consumption of alternative fuels, and reduce petroleum consumption.

Battelle Energy Alliance, LLC, managing and operating contractor for Idaho National Laboratory (INL), is the lead laboratory for the U.S. Department of Energy's advanced vehicle testing and manages the Advanced Vehicle Testing Activity Federal Fleet Vehicle Data Logging and Characterization Study, which promotes utilization of advanced electric drive vehicle transportation technologies. The Advanced Vehicle Testing Activity focuses its testing activities on emerging and newly commercialized plug-in electric vehicle (PEV) technologies because of the high-energy efficiency achieved and reduced consumption of petroleum by electric-drive vehicles. Battelle Energy Alliance, LLC selected Intertek Testing Services, North America (Intertek) to support the collection of data on federal fleet operations and report the findings on vehicle and mission characterizations to support successful introduction of PEVs into federal fleets.

More fuel-efficient internal combustion engine (ICE) vehicles, including hybrid electric vehicles, exist that may provide improvements for the current fleet; however, this study's focus is on replacing ICE vehicles with suitable PEVs.

Because of the large number of vehicles in federal fleets in the United States, these fleets provide a substantial opportunity for introduction of battery electric vehicles (BEVs) and plug-in hybrid electric vehicles (PHEVs) (collectively referred to as PEVs). However, to assess the scale of this opportunity, additional data are required to characterize the various missions performed by each fleet and to determine which existing vehicles are most suitable for replacement by a PEV.

Table 1 identifies the agencies selected for analysis in this project. The total number of vehicles in the agency's fleet is shown, along with the number of vehicles that were monitored as part of the study. The results for those monitored vehicles can be extrapolated to a larger fleet of similar vehicles, which is also shown in the table.

Each of these agencies received reports on the study pertaining directly to their monitored vehicles and extrapolated fleet of vehicles. These reports, available at http://avt.inl.gov/, characterized the mission and travel of the monitored vehicles, along with observations on potential PEV replacement. The replacement, using the listed PEVs, resulted in calculations of savings in fuel cost and greenhouse gas (GHG) emissions. Those results were extrapolated to full fleet benefits. This report aggregates the results over all of the agencies' fleets.

\footnotetext{
${ }^{1}$ http://thomas.loc.gov/cgi-bin/query/z?c102:h.r.776.enr [accessed March 16, 2015]

${ }^{2}$ http://www.gpo.gov/fdsys/pkg/BILLS-109hr6enr/pdf/BILLS-109hr6enr.pdf [accessed March 16, 2015].

${ }^{3}$ http://www.gsa.gov/portal/content/102452 [accessed March 16, 2015].

${ }^{4}$ https://www.fedcenter.gov/programs/eo13514/ [accessed March 16, 2015].

${ }^{5}$ http://www.gpo.gov/fdsys/pkg/PLAW-110publ140/pdf/PLAW-110publ140.pdf [accessed March 16, 2015 ].
} 
Table 1. Agencies and vehicles for the Advanced Vehicle Testing Activity Federal Fleet Vehicle Data Logging and Characterization Study.

\begin{tabular}{|c|c|c|c|c|c|c|}
\hline Agency & Location & Acronym & State & $\begin{array}{c}\text { Full } \\
\text { Vehicle } \\
\text { Fleet Size }\end{array}$ & $\begin{array}{l}\text { Vehicles } \\
\text { Monitored }\end{array}$ & $\begin{array}{c}\text { Extrapolated } \\
\text { Fleet Size }\end{array}$ \\
\hline $\begin{array}{l}\text { National Park } \\
\text { Service }\end{array}$ & $\begin{array}{l}\text { Golden Gate National } \\
\text { Recreational Area }\end{array}$ & GGNRA & California & 182 & 14 & 105 \\
\hline $\begin{array}{l}\text { National Park } \\
\text { Service }\end{array}$ & $\begin{array}{c}\text { Fort Vancouver } \\
\text { National Historic Site }\end{array}$ & FVNHS & Washington & $\begin{array}{c}\text { Not } \\
\text { Available }\end{array}$ & 3 & Not Available \\
\hline $\begin{array}{l}\text { National Park } \\
\text { Service }\end{array}$ & $\begin{array}{l}\text { Grand Canyon } \\
\text { National Park }\end{array}$ & GCNP & Arizona & 232 & 11 & 218 \\
\hline $\begin{array}{l}\text { National Park } \\
\text { Service }\end{array}$ & $\begin{array}{l}\text { Rocky Mountain } \\
\text { National Park }\end{array}$ & RMNP & Colorado & 240 & 8 & 164 \\
\hline $\begin{array}{l}\text { National Park } \\
\text { Service }\end{array}$ & $\begin{array}{l}\text { Sleeping Bear Dunes } \\
\text { National Lakeshore }\end{array}$ & SLBE & Michigan & 59 & 14 & 52 \\
\hline $\begin{array}{l}\text { United States Forest } \\
\text { Service }\end{array}$ & $\begin{array}{l}\text { Caribou-Targhee } \\
\text { National Forest }\end{array}$ & CTNF & $\begin{array}{l}\text { Idaho, Utah, } \\
\text { and } \\
\text { Wyoming }\end{array}$ & $\begin{array}{c}\text { Not } \\
\text { available }\end{array}$ & 12 & 66 \\
\hline $\begin{array}{c}\text { National } \\
\text { Aeronautics and } \\
\text { Space } \\
\text { Administration }\end{array}$ & $\begin{array}{c}\text { White Sands Test } \\
\text { Facility }\end{array}$ & WSTF & New Mexico & 137 & 10 & 105 \\
\hline $\begin{array}{c}\text { National } \\
\text { Aeronautics and } \\
\text { Space } \\
\text { Administration }\end{array}$ & $\begin{array}{l}\text { Glenn Research } \\
\text { Center }\end{array}$ & GRC & Ohio & 108 & 10 & 20 \\
\hline $\begin{array}{c}\text { National } \\
\text { Aeronautics and } \\
\text { Space } \\
\text { Administration }\end{array}$ & Stennis Space Center & $\mathrm{SSC}$ & Mississippi & $\begin{array}{c}\text { Not } \\
\text { available }\end{array}$ & 12 & Not available \\
\hline $\begin{array}{l}\text { U.S. Department of } \\
\text { Homeland Security }\end{array}$ & $\begin{array}{l}\text { U.S. Coast Guard } \\
\text { Headquarters }\end{array}$ & USCG & $\begin{array}{l}\text { Washington } \\
\text { D.C. }\end{array}$ & $\begin{array}{c}\text { Not } \\
\text { available }\end{array}$ & 10 & Not available \\
\hline $\begin{array}{l}\text { U.S. Department of } \\
\text { Health/Human } \\
\text { Services }\end{array}$ & $\begin{array}{l}\text { Assistant Secretary } \\
\text { Preparedness and } \\
\text { Response }\end{array}$ & ASPR & $\begin{array}{l}\text { Maryland/ } \\
\text { Virginia }\end{array}$ & $\begin{array}{c}\text { Not } \\
\text { available }\end{array}$ & 8 & Not available \\
\hline $\begin{array}{l}\text { Department of } \\
\text { Veterans Affairs }\end{array}$ & $\begin{array}{l}\text { James J. Peters VA } \\
\text { Medical Center-Bronx }\end{array}$ & $\mathrm{VA}-\mathrm{Br}$ & New York & 50 & 9 & 23 \\
\hline $\begin{array}{l}\text { Department of } \\
\text { Veterans Affairs }\end{array}$ & $\begin{array}{l}\text { VA - Manhattan } \\
\text { Campus }\end{array}$ & VA-Man & New York & 100 & 9 & 59 \\
\hline $\begin{array}{c}\text { National Institutes of } \\
\text { Health }\end{array}$ & Bethesda Campus & $\mathrm{NIH}$ & Maryland & 264 & 20 & 264 \\
\hline $\begin{array}{l}\text { U.S. Department of } \\
\text { Energy }\end{array}$ & $\begin{array}{c}\text { Idaho National } \\
\text { Laboratory }\end{array}$ & INL & Idaho & 378 & 12 & 378 \\
\hline
\end{tabular}

\section{PROJECT OBJECTIVE}

This study explored federal fleet vehicles and their usage characteristics, with a primary goal of supporting the goals of Presidential Executive Order 13514, which includes the following:

- Pursuing opportunities with vendors and contractors to address and incentivize GHG emission reductions and petroleum use reductions

- Implementing strategies and accommodations for transit, travel, training, and conferences that actively reduce carbon emissions associated with commuting and travel by agency staff 
- Meeting GHG emissions reductions associated with other federal government sustainability goals

- Implementing innovative policies and practices that address agency-specific Scope 3 GHG emissions. ${ }^{6}$

Because of the large number of vehicles in the federal fleets, there is a substantial opportunity for PHEV and BEV adoption. Federal fleets offer an opportunity as a market for alternative fuels due to their scale, refueling patterns, and regular vehicle turnover. ${ }^{7}$

This project had the following four defined tasks:

1. Data collection: Coordinate with the fleet manager to collect data on agency fleet vehicles. This includes collecting information on the fleet vehicle and installing data loggers on a representative sample of the fleet vehicles to characterize their missions.

2. Data analysis and review: Examine the data collected by the loggers and fleet vehicle characteristics to describe typical fleet activity. Incorporate fleet manager's input on introducing PEVs to the agency's fleet.

3. PEV implementation feedback: Provide feedback to fleet personnel and Battelle Energy Alliance, LLC on the selection criteria for replacement PEVs in their specific fleet vehicle missions.

4. Observations and recommendations: Provide actionable information to introduce PEVs into agency fleet operations and assess any related impacts for the facility.

Data collected from vehicles include trip distance, idle time, time between uses, and stop locations. Data collection continued for 30 to 60 days on each site using a non-intrusive data logger, which gathered and transmitted information using a global positioning system and cellular service. The loggers collected data at 1-minute intervals and transmitted when an active signal was present.

Extrapolating the results of this analysis to the larger fleet provides estimates of potential savings in gasoline consumption and GHG emissions. Individual agency reports also provided recommendations relating to fleet management of BEVs and PHEVs for additional consideration.

Agency fleet managers may use the information supplied in these reports to help them identify which vehicles are candidates for replacement by a BEV or a PHEV based on their use and mission. BEVs are preferred because of the greater potential reduction of GHG emissions, fuel cost, and petroleum usage; however, they are not likely to be suitable for all vehicle missions.

In the larger sense, the information in this final report aggregates results for all agencies' fleets to provide an overview of federal fleets, vehicle missions, vehicle uses, and so forth. All federal agencies may be able to use this information to plan and establish a more systematic method for adoption of BEVs and PHEVs in their respective agencies.

\section{METHODS}

\subsection{Fleet Vehicle Survey}

This study monitored 162 fleet vehicles. Agency fleet managers selected fleet vehicles from their facility for study and provided basic information for each vehicle, including its managing department, home base for the vehicle, contact information, primary vehicle mission, vehicle ownership, fuel type, and odometer reading. Through the course of each study, some vehicles failed to provide data or provided insufficient data for various reasons. Meaningful data were collected on 153 vehicles. The vehicles monitored were a mix of General Services Administration (GSA) and agency vehicles.

\footnotetext{
${ }^{6} \mathrm{http}: / /$ energy.gov/sites/prod/files/2013/10/f3/eo13514.pdf [accessed March 16, 2015].

${ }^{7}$ Fleet Purchase Behavior: Decision Processes and Implications for New Vehicle Technologies and Fuel, Nesbitt, Sperling, University of California, Davis 2001.
} 


\subsection{Data Collection}

Individual privacy concerns exist when monitoring vehicle movement with data loggers. Data collection occurs by vehicle identification as identified by Intertek, data logger number, and vehicle identification number or agency-assigned vehicle number. No information was collected relating to the vehicle operator and no raw data was provided to the fleet managers. In this manner, nothing is collected, analyzed, or reported on that relates to individual driving habits.

\subsubsection{Data Logger}

Non-intrusive data loggers, produced by $\operatorname{InTouchMVC}{ }^{8}$ and depicted in Figure 1, were inserted into the vehicle's onboard diagnostic port to collect and transmit relevant data. Installation of the data logger and manual recording of information about the vehicle that ties the logger and vehicle together in the data, typically takes less than 5 minutes. Once installed and activated (during vehicle use), the data loggers collect vehicle information once every minute during vehicle operation and transmit by cellular communication to the data center.

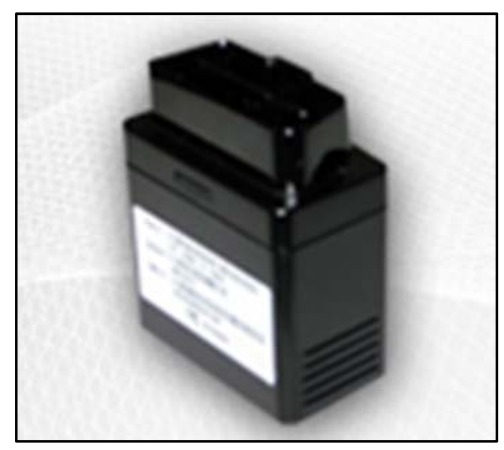

Figure 1. InTouchMVC data logger.

Data logger connectivity and data transmission was verified to ensure full data sets were collected. Missing data (i.e., reported as "null" values) were frequently the result of lost global positioning system reception, logger device removal, or extended periods in regions with insufficient cellular reception. Vehicle and data logger information was filtered and if these null values presented a significant impact on the data collected and no resolution was possible. This report also identifies the statistics on this validation process.

\subsubsection{Data Captured}

Data consist of key-on events, key-off events, and position updates logged every minute while the vehicle is keyed-on. InTouchMVC converted these data points into records of trip events, stop events, and idle events.

From these data points, the following information was available for evaluation:

- Trip start and stop time and location

- Trip distance and duration

- Idle start time, location, and duration

- Stop start time, location, and duration

\footnotetext{
${ }^{8}$ www.intouchmvc.com [accessed March 16, 2015].
} 


\subsection{Data Analysis}

\subsubsection{Definitions}

Figure 2 illustrates a vehicle outing, which is comprised of trips, stops, and idle events, that may occur during one day or over several days. The following list provides a definition of these terms:

1. Outing: An outing is the combination of trips and stops that begin at the home base and includes all travel until the vehicle returns home.

2. Trip: A trip begins with a key-on event and ends with the next key-off event.

3. Vehicle stop: A vehicle stop includes a key-off/key-on event pair.

4. Idle time: Idle time is the amount of time a vehicle spends stationary after a key-on event when the vehicle is not moving for a period of 3 minutes or longer.

5. Trip travel time: Trip travel time is the amount of time required to complete a trip, excluding stops but including idle time.

Definitions of additional analysis and survey terms are as follows:

1. Operating shift: Fleet manager-defined period worked.

2. Study days: Days during which the data loggers are connected.

3. Vehicle days: Study days during which a vehicle is used.

4. Null values: Data record unusable for analysis for various reasons.

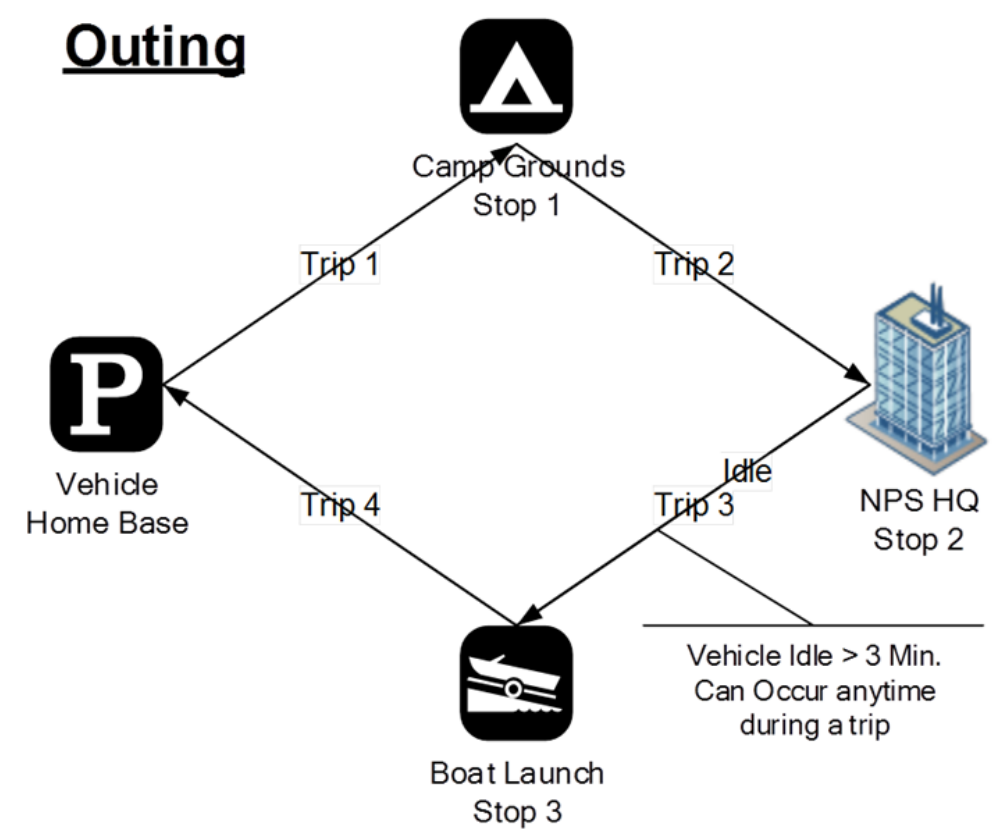

Figure 2. Example vehicle outing.

\subsubsection{Data Evaluation}

Processing the data involves removal of null values and aggregation by different spatial and temporal scales. Aggregation was by day, by trip, and by outing to produce figures showing the patterns of use. Aggregation by vehicle mission followed to characterize use for the agency fleet. Section 5 presents these results by mission assigned. Data were extrapolated to provide overall fleet usage and benefit analysis when fleet information was provided. Section 6 presents these aggregated benefits; observations are included in Section 7. 
Statistical data analysis used Python 2.7 with the MATLAB Plotting Library graphics environment (Matplotlib) and spatial display with ESRI ArcGIS. ${ }^{9}$ Some analysis also used Microsoft Excel ${ }^{10}$ and Tableau software. ${ }^{11}$ Frequency distributions summarize the travel behavior of each vehicle and vehicle mission during the study period.

\section{VEHICLES \\ 4.1 Vehicle Missions}

Vehicle mission is an important characteristic in the fleet study. Information used to define vehicle mission includes the vehicle's configuration, vehicle use, classification per 40 CFR Part 600.315-82 and the Environmental Protection Agency (EPA), participating agency use, and generally assumed vehicle use. Based on fleet information gathered, the following seven mission/vehicle categories were established for analysis (Figure 3):

1. Pool vehicles: A pool vehicle is any automobile (other than the low-speed vehicles identified below) manufactured primarily for use in passenger transportation, with not more than 10 passengers.

2. Enforcement vehicles: Vehicles specifically approved in an agency's appropriation act for use in apprehension, surveillance, police, or other law enforcement work. This category also includes site security vehicles, parking enforcement, and general use, but the vehicles are capable of requirements to support enforcement activities.

3. Support vehicles: Vehicles assigned to a specific work function or group to support the mission of that group. Vehicles are generally passenger vehicles or light-duty pickup trucks and may contain after-market modifications to support the mission.

4. Transport vehicles: Light, medium, or heavy-duty trucks used to transport an operator and tools or equipment of a non-specific design or nature. The vehicle's possible uses include repair, maintenance, and delivery.

5. Specialty vehicles: Vehicles designed to accommodate a specific purpose or mission (such as ambulances, mobile cranes, and handicap access assistance).

6. Shuttles/buses: Vehicles designed to carry more than 12 passengers and further outlined in 49 CFR 532.2.

7. Low-speed vehicle: Vehicles that are legally limited to roads with posted speed limits up to $45 \mathrm{mph}$ and that have a limited load-carrying capability.

\footnotetext{
${ }^{9}$ www.esri.com [accessed January 10, 2014].

${ }^{10} \mathrm{http}: / /$ www.microsoftstore.com [accessed January 7, 2015].

${ }^{11}$ http://www.tableausoftware.com/ [accessed January 7, 2015].
} 


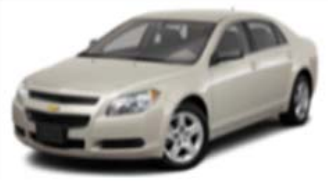

Pool Vehicle

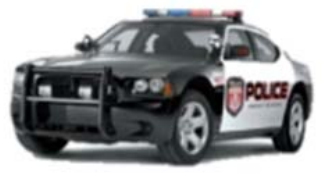

Enforcement Vehicle

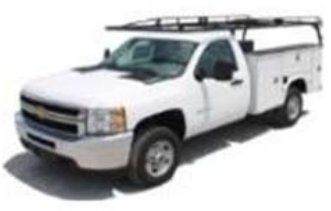

Support Vehicle

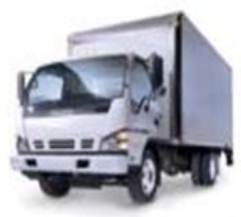

Transport Vehicle

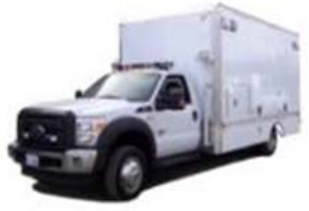

Specialty Vehicle

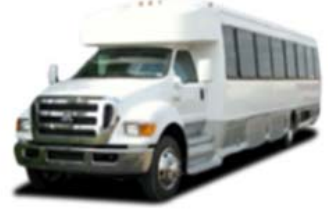

Shuttle / Bus

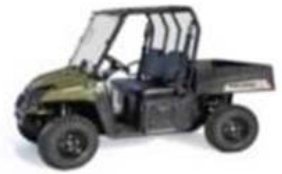

Low Speed

Vehicles

Figure 3. Vehicle missions.

\subsection{Alternative Fuel Vehicles}

The adoption of PHEVs and BEVs is a primary goal of GSA and supports the directives previously referenced.

As GSA increases its certification of PHEVs and BEVs, agencies can plan for vehicle replacement through GSA for passenger vehicles and trucks. Table 2 presents the replacement requirements for fleet vehicles. Note that both the age and mileage requirements need to be met in order for the vehicle to qualify for replacement, except where noted as "or."

Table 2. GSA vehicle replacement requirements.

\begin{tabular}{|c|c|c|c|}
\hline \multicolumn{4}{|c|}{ GSA Vehicle Replacement Requirements ${ }^{12}$} \\
\hline & Fuel Type & Years & Miles \\
\hline \multirow{6}{*}{ Passenger vehicles } & \multirow{4}{*}{$\begin{array}{l}\text { Gasoline or } \\
\text { alternative fuel } \\
\text { vehicle }\end{array}$} & 3 & 36,000 \\
\hline & & 4 & 24,000 \\
\hline & & 5 & Any mileage \\
\hline & & Any age & 75,000 \\
\hline & Hybrid & 5 & Any mileage \\
\hline & Low-Speed BEV & 6 & Any mileage \\
\hline \multirow{3}{*}{ Light trucks 4 × 2} & Non-diesel & 7 or & 65,000 \\
\hline & Diesel & 8 or & 150,000 \\
\hline & Hybrid & 7 & Any mileage \\
\hline \multirow{3}{*}{ Light trucks 4 x 4} & Non-diesel & 7 or & 60,000 \\
\hline & Diesel & 8 or & 150,000 \\
\hline & Hybrid & 7 & Any mileage \\
\hline \multirow{2}{*}{ Medium trucks } & Non-diesel & 10 or & 100,000 \\
\hline & Diesel & 10 or & 150,000 \\
\hline \multirow{2}{*}{ Heavy Trucks } & Non-diesel & 12 or & 100,000 \\
\hline & Diesel & 12 or & 250,000 \\
\hline
\end{tabular}

\footnotetext{
${ }^{12}$ http://www.gsa.gov/graphics/fas/VehicleReplacementStandardsJune2011Redux.pdf [accessed March 16, 2015].
} 


\subsection{Battery Electric Vehicle and Plug-in Hybrid Electric Vehicle Benefits and Challenges}

BEVs are fully powered by the battery energy storage system available onboard the vehicle. The Nissan Leaf is an example of a BEV. Because the BEV has no other energy source for propulsion, the range, power requirements, and mission of the needed vehicle factor greatly in purchasing decisions. Maximizing BEV capabilities typically requires batteries more than an order of magnitude larger in capacity than the batteries in hybrid electric vehicles.

PHEVs obtain their power from at least two energy sources. The typical PHEV configuration uses a battery and an ICE, powered by either gasoline or diesel. PHEV designs differ between manufacturers. All have a charge-depleting (CD) mode, where the battery is depleted of its stored energy to propel the vehicle, and a charge-sustaining (CS) mode (or extended-range mode), which is entered after CD mode is complete Some PHEVs' operation in CD mode is purely electric, while others employ the engine to supplement the battery power during the initial battery depletion to a set state of charge (usually below $50 \%$ ), with the latter known as blended CD mode. CS mode involves a combination of propulsion power of battery and ICE, while the state of charge of the battery is maintained between set limits.

\subsubsection{Battery Electric Vehicle Benefits/Challenges}

\section{EPA identifies the following benefits of BEVs: ${ }^{13}$}

- Energy efficient: Electric vehicles convert about 59 to $62 \%$ of the electrical energy from the grid to power at the wheels, whereas conventional gasoline vehicles only convert about 17 to $21 \%$ of the energy stored in gasoline to power at the wheels.

- Environmentally friendly: PEVs emit no tailpipe pollutants, although the power plant producing the electricity may emit them. Electricity from nuclear, hydro, solar, or wind-powered plants causes no air pollutants.

- Performance benefits: Electric motors provide quiet, smooth operation and exhibit maximum torque at zero and low speeds, while also requiring less maintenance than ICEs.

- Reduce energy dependence: Electricity is a domestic energy source.

The EPA also identifies the following challenges associated with BEVs:

- Driving range: Most BEVs can only travel about 100 to 200 miles (or less) before recharging, whereas gasoline vehicles can often travel over 300 miles before refueling and some much further.

- Recharge time: Fully recharging the battery pack can take 4 to 8 hours. With a high-power direct current fast charger (DCFC), restoration from a depleted state to $80 \%$ capacity can take approximately 30 minutes.

- Battery cost: The large battery packs are expensive and may need to be replaced one or more times.

- Bulk and weight: Battery packs are heavy and take up considerable vehicle space.

\subsubsection{Plug-in Hybrid Electric Vehicle Benefits/Challenges}

EPA identifies the following benefits of PHEVs: ${ }^{14}$

- Less petroleum use: PHEVs are expected to use about 40 to $60 \%$ less petroleum than conventional vehicles. Because electricity is produced primarily from domestic resources, PHEVs reduce dependence on oil.

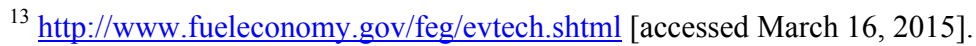

${ }^{14}$ http://www.fueleconomy.gov/feg/phevtech.shtml [accessed March 16, 2015].
} 
- Fewer emissions: PHEVs are expected to emit fewer GHG emissions than conventional vehicles, but as with BEVs, the difference depends largely on the type of power plant supplying the electricity.

- Higher vehicle costs, lower fuel costs: PHEVs will likely cost $\$ 1,000$ to $\$ 7,000$ more than comparable non-PHEVs. Fuel will cost less because electricity is much cheaper than gasoline, but the fuel savings depends on how much driving is done with the off-board electrical energy.

- Recharging takes time: Recharging the battery typically takes several hours. However, PHEVs do not have to be plugged in to be driven. They can be fueled solely with gasoline, but will not achieve maximum range, fuel economy, or fuel savings without charging.

- Measuring fuel economy: Because a PHEV can operate on electricity alone, gasoline alone, or a mixture of the two, EPA provides a fuel economy estimate for gasoline-only operation (CS mode), electric-only operation (all-electric CD mode), or combined gasoline and electric operation (blended CD mode).

In most cases, the PEV retail cost is higher than a non-PEV model. This incremental purchase cost may be a fleet budget challenge; however, many original equipment manufacturers (OEMs) have offered incentives to encourage the use and adoption of BEVs and PHEVs. Some OEMs have recently reduced vehicle cost, while also increasing vehicle range. Additionally, federal and state incentives have increased the attractiveness of purchasing a PEV. A common assumption is that increasing PEV sales will result in a reduction in this incremental purchase cost and a positive feedback loop will ensue.

\subsection{Plug-In Electric Vehicle Availability}

GSA provides a summary of light and medium-duty passenger vehicles available for lease or purchase through the GSA portal, ${ }^{15}$ although not all BEVs and PHEVs currently on the market are 'certified' to be GSA replacements. Vehicles not on the GSA list of 'certified' vehicles require an agency to self-certify a functional need or provide alternative measures for exemptions. Table 3 summarizes the vehicles that may be suitable replacements and are certified replacements through GSA. Note that the "CD/CS" column provides the EPA fuel economy values for the CD and CS modes of PHEVs, while the city and highway fuel economy values are provided for BEVs. Fuel economy of the PHEV CD mode and BEVs is provided in units of miles-per-gallon-of-gasoline-equivalent (MPGe). This metric allows electricity consumption to be compared with fuel consumption during CS mode (or against conventional vehicles). The Nissan Leaf and Mitsubishi i-MiEV were not included in the alternative fuel guide available at this writing, but they have appeared in previous guides.

Tables 3 and 4 provide summaries of PHEVs and BEVs currently listed by GSA. Tables 5 through 8 provide summaries of PEVs either currently available or near commercialization for all vehicle types and include those on the GSA list. These vehicles may qualify for use by the agency through demonstrating a functional need.

Table 3. GSA-certified PHEVs for 2015.

\begin{tabular}{lcccc}
\multicolumn{1}{c}{ Make/Model } & GSA Class & Type & CD/CS & GSA Incremental Price \\
\hline Chevrolet Volt* & Sedan, Subcompact & PHEV & $98 \mathrm{MPGe} / 37 \mathrm{mpg}$ & $\$ 17,692.17$ \\
Ford C-MAX Energi & Sedan, Subcompact & PHEV & $88 \mathrm{MPGe} / 38 \mathrm{mpg}$ & $\$ 14,062.23$ \\
Ford Fusion Energi & Sedan, Compact & PHEV & $88 \mathrm{MPGe} / 38 \mathrm{mpg}$ & $\$ 13,640.05$ \\
\hline
\end{tabular}

* The Chevrolet Volt has an all-electric CD mode rated for 38 miles. The Ford vehicles have blended CD modes rated for 20 miles.

${ }^{15}$ http://www.gsa.gov/portal/content/104224 [accessed June 23, 2015]. 
Table 4. GSA-certified BEVs for 2015.

\begin{tabular}{lcccc}
\multicolumn{1}{c}{ Make/Model } & GSA Class & Type & City/Highway & GSA Incremental Price \\
\hline Ford Focus Electric & Sedan, Subcompact & BEV & $110 / 99$ MPGe & $\$ 11,351.15$ \\
Smart Fortwo ED & Sedan, Microcompact & BEV & $123 / 93 \mathrm{MPGe}$ & $\$ 7,277.05$ \\
\hline
\end{tabular}

Note that EPA differs from GSA in vehicle class designation. EPA identifies the Volt as a compact, the C-MAX Energi as a midsize, the Fusion Energi as a midsize, and the Focus Electric as a compact. ${ }^{16}$

Table 5. OEM PHEV cars and availability.

\begin{tabular}{cccc}
\hline Make & EPA Class & Model & $\begin{array}{c}\text { Initial Model Year/Estimated } \\
\text { Year for Commercialization }\end{array}$ \\
\hline Chevrolet & Compact & Volt & 2011 \\
Ford & Midsize & C-MAX Energi & 2013 \\
Ford & Midsize & Fusion Energi & 2013 \\
Toyota & Midsize & Prius PHEV & 2012 \\
Honda & Midsize & Accord PHEV* & 2014 \\
Cadillac & Subcompact & ELR & 2014 \\
Porsche & Large & Panamera S E-Hybrid & 2014 \\
BMW & Subcompact & i3 REx & 2014 \\
BMW & Subcompact & i8 & 2014 \\
Hyundai & Midsize & Sonata PHEV & 2015 (estimate) \\
Audi & Compact & A3 e-tron & 2016 (estimate) \\
Mercedes & Subcompact & C350 PHEV & 2016 (estimate) \\
Mercedes & Large & S550 PHEV & 2016 (estimate) \\
\hline
\end{tabular}

* Honda did not release a MY2015 Accord PHEV; the return of this vehicle model is uncertain.

Table 6. OEM BEV cars and availability.

\begin{tabular}{cccc}
\hline Make & EPA Class & Model & $\begin{array}{c}\text { Initial Model Year/Estimated } \\
\text { Year for Commercialization }\end{array}$ \\
\hline Nissan & Midsize & Leaf & 2011 \\
Ford & Compact & Focus Electric & 2012 \\
Tesla & Large & Model S & 2012 \\
Mitsubishi & Subcompact & i-MiEV* & 2012 \\
Fiat & Mini & $500 \mathrm{e}$ & 2013 \\
Honda & Small Station Wagon & Fit EV & 2013 \\
smart & Two Seater & Fortwo ED & 2013 \\
BMW & Subcompact & i3 & 2014 \\
Chevrolet & Subcompact & Spark EV & 2014 \\
Kia & Small Station Wagon & Soul EV & 2014 \\
Volkswagen & Compact & e-Golf & 2015 \\
Mercedes-Benz & Midsize & B-Class Electric Drive & 2015 \\
\hline
\end{tabular}

* Mitsubishi did not manufacture a MY15 i-MiEV; the vehicle returned in the 2016 MY.

${ }^{16} \mathrm{http}: / /$ www.fueleconomy.gov/feg/Find.do?action=sbs\&id=34130 [accessed March 16, 2015]. 
Table 7. OEM PHEV trucks, vans, and availability.

\begin{tabular}{cccc} 
Make & EPA Class & Model & $\begin{array}{c}\text { Initial Model Year/Estimated } \\
\text { Year for Commercialization }\end{array}$ \\
Via & Standard Pickup Truck & VTRUX VR300 & 2013 \\
Via & Special Purpose Vehicle & VTRUX Cargo Van & 2013 \\
Via & Vans, Cargo Type & VTRUX Pass Van & 2013 \\
Mitsubishi & Small SUV & Outlander PHEV & 2016 (estimate) \\
\hline
\end{tabular}

Table 8. OEM BEV trucks, vans, and availability.

\begin{tabular}{cccc} 
Make & EPA Class & Model & $\begin{array}{c}\text { Initial Model Year/Estimated } \\
\text { Year for Commercialization }\end{array}$ \\
\hline Tesla & Standard SUV & Model X & 2015 (estimate) \\
Nissan & Van & e-NV200 & 2016 (estimate) \\
\hline
\end{tabular}

As further indication of the expanding market for PEVs, companies are offering after-market vehicle upgrades involving the addition of plug-in capabilities to OEM vehicles. For example, Echo Automotive headquartered in Scottsdale, Arizona offers a "...low-cost, bolt-on, plug-in hybrid system that can quickly be installed on new or existing fleet vehicles to increase fuel efficiency and decrease operating costs - all without affecting the OEM power train or requiring costly infrastructure." ${ }^{17}$ EVAOS conducts upgrades of Ford F-series pickup trucks to PHEV models and has delivered vehicles to the U.S. Air Force ${ }^{18}$. Options such as these conversions might be of benefit for fleet vehicles for which no replacement PEV is currently available.

\subsection{Plug-In Electric Vehicle Charging}

Refueling electric vehicles presents some challenges and some opportunities not encountered when refueling petroleum-fueled vehicles. Recharging the battery of a PHEV follows the same methodology as that for BEVs. This section provides basic information on recharging PEVs.

\subsubsection{Electric Vehicle Supply Equipment Design}

4.5.1.1 Charging Components. Electric vehicle supply equipment (EVSE) stations deliver electric power from the utility to the applicable charge port on the vehicle. Figure 4 illustrates the primary components of a typical conductive, alternating current (AC) Level 2EVSE unit.

\footnotetext{
${ }^{17} \mathrm{http}: / /$ www.echoautomotive.com/index.php?option=com content\&view=article\&id=8 $[\operatorname{accessed}$ March 15, 2015].

${ }^{18}$ http://www.evaos.com [accessed March 16, 2015].
} 


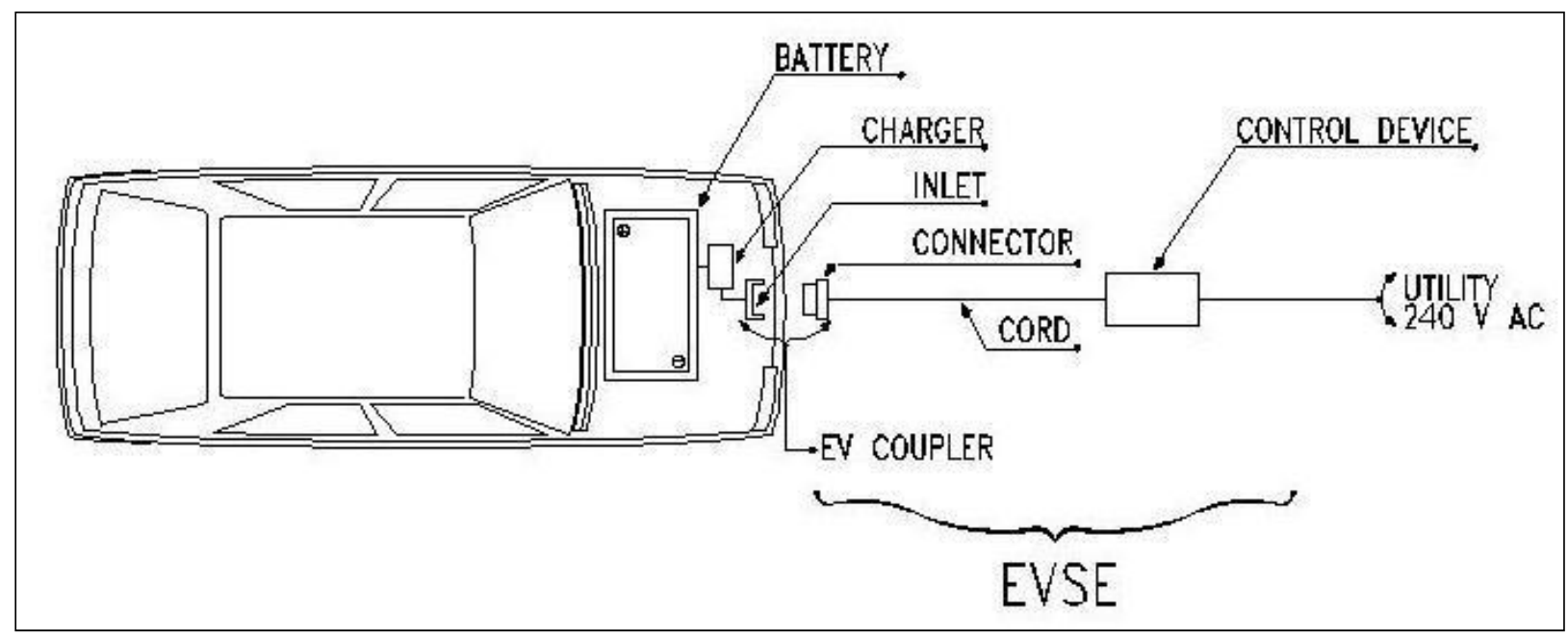

Figure 4. AC Level 2 charging diagram. ${ }^{19}$

The electric utility delivers AC current to the charging location. Conversion from AC to the DC electricity necessary for battery charging can occur either on or off board the vehicle. Section 4.5.1.2 provides further explanation of the different EVSE configurations. For onboard conversion, AC current flows through the PEV inlet to the onboard charger. The charger converts AC to the DC current required to charge the battery. A connector attached to the EVSE inserts into a PEV inlet to establish an electrical connection to the PEV for charging and information/data exchange. Off-board conversion, also known as DC charging, proceeds in a similar manner except that the AC to DC conversion occurs in a charger that is off board the vehicle and, thus, bypasses any onboard charger. For both AC and DC charging, the PEV's battery management system on board the vehicle controls the battery rate of charge, among other functions. All current PEVs have an onboard charger; some BEVs (but no PHEVs currently available in the United States) accommodate DC charging.

4.5.1.2 Charging Configurations and Ratings. The Society of Automotive Engineers (SAE) standardized the requirements, configurations, and equipment followed by most PEV suppliers in the United States in the $\mathrm{J} 1772^{\mathrm{TM}}$ standard. Figure 5 summarizes these attributes and the estimated recharge times. Actual recharge times depend on the onboard equipment, including the charger, battery, and battery management system.

${ }^{19}$ http://avt.inl.gov/pdf/EVProj/EVChrgInfraDeployGuidelinesPhoenixVer3.2.pdf [accessed March 16, 2015]. 


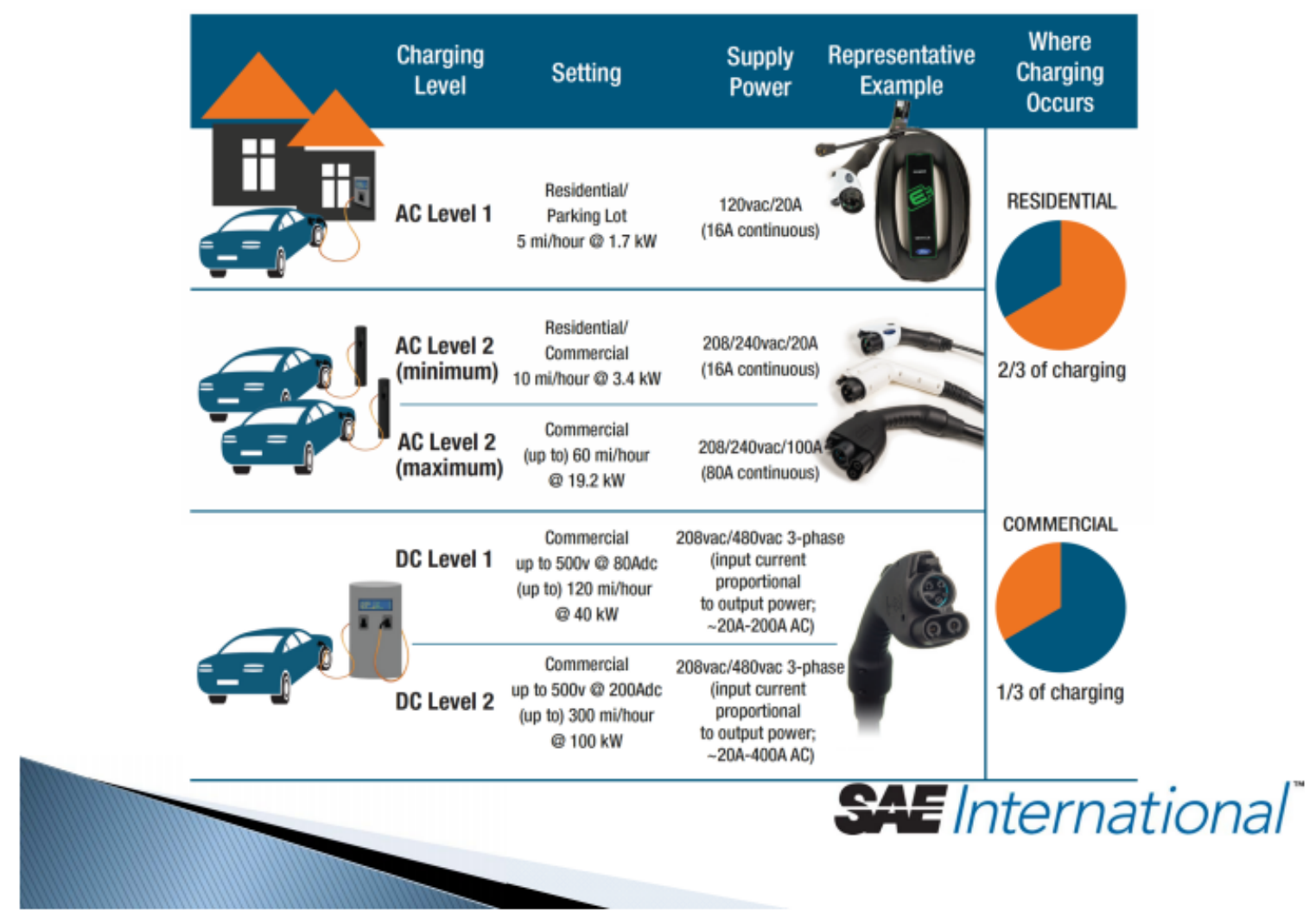

Figure 5. SAE charging configurations and ratings terminology. ${ }^{20}$

PEVs are typically sold with an AC Level 1 cordset included. This cordset is generally intended to be used when a 120-volt electrical outlet is available (and a slower charge rate is acceptable) or in emergencies when the vehicle is away from installed AC Level 2 EVSE. A typical cordset is shown in Figure 6.

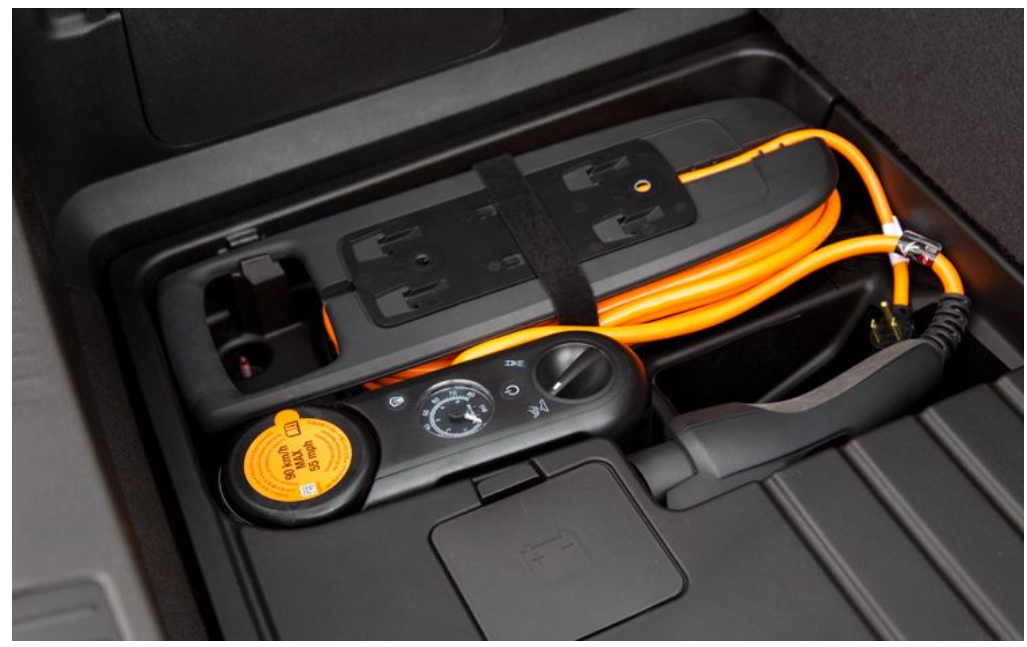

Figure 6. Chevrolet Volt AC Level 1 cordset. $^{21}$

AC recharging capabilities found in the public arena more typically are AC Level 2. Figure 7 depicts a typical SAE J1772-compliant inlet and connector for both AC Levels 1 and 2.

\footnotetext{
${ }^{20} \mathrm{http}: / /$ www.sae.org/events/gim/presentations/2013/pev_charging_standards_status.pdf [accessed June 25, 2015].

${ }^{21}$ www.pluginamerica.org.
} 


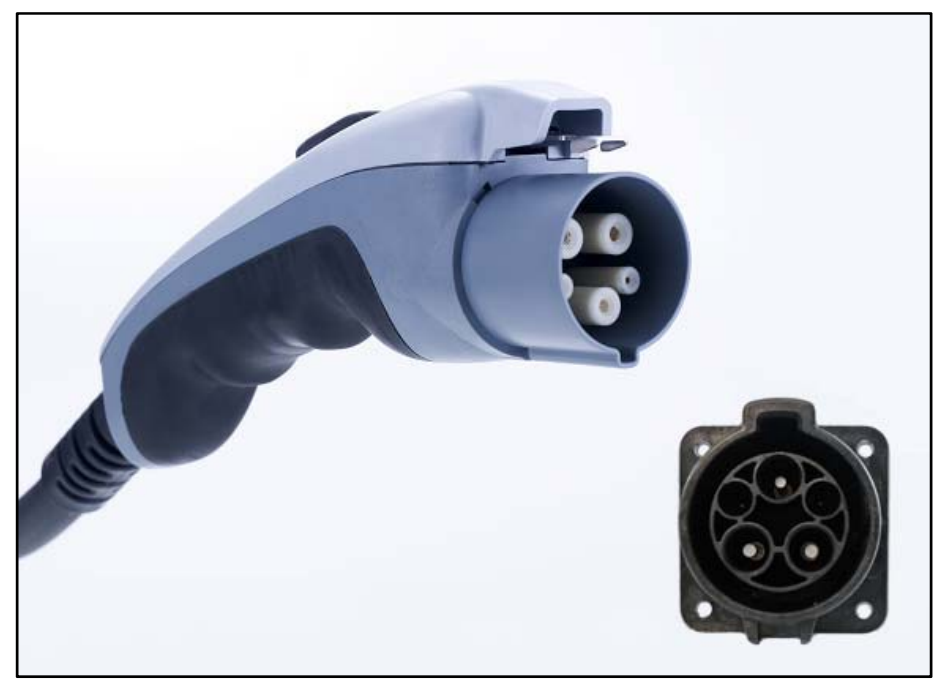

Figure 7. SAE J1772 connector and inlet. ${ }^{22}$

The J1772 standard also identifies requirements for DC charging. For PEVs that accept both AC and DC inputs, the SAE approved a single connector and inlet design, known as the combined charging system. Figure 8 shows this connector, which is colloquially known as the J1772 "combo connector."
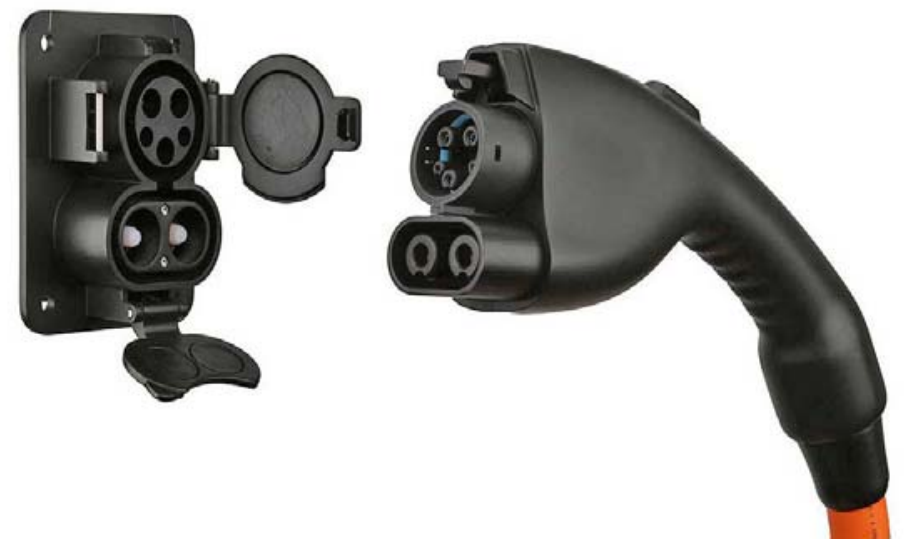

Figure 8. J1772-compliant combo connector. ${ }^{23}$

Some BEVs introduced in the United States prior to the approval of the J1772 standard for DC charging employ the CHAdeMO (designed in Japan) standard for connector and inlet design. Figure 9 shows this connector. DC EVSE units that are either J1772-compliant or CHAdeMO-compliant are both known as DCFCs. Tesla Motors has installed proprietary EVSE units for their vehicles because these vehicle do not meet either DCFC standard; however, Tesla offers adapters for their vehicles that allow for charging at $\mathrm{J}_{1772}$ AC Level 2 and CHAdeMO EVSE. ${ }^{24}$

The presence of the three separate standards for DC charging presents challenges for vehicle owners to ensure the EVSE accessed provides the appropriate connector for their vehicle inlet. Not all PEV suppliers include DC charging options. BEV suppliers have provided DC inlets, where PHEV suppliers have not, because the rapid recharging provides opportunities for expanded vehicle range with minimal operator wait

\footnotetext{
$22 \mathrm{http://carstations.com/types/j09} \mathrm{[accessed} \mathrm{March} \mathrm{16,} \mathrm{2015].}$

${ }^{23} \mathrm{http}: / / w w w . z e m o t o r i n g . c o m / n e w s / 2012 / 10 /$ sae-standardizes-j1772-fast-dc-charging-up-to-100-kw [accessed March 16, 2015].

${ }^{24}$ http://www.teslamotors.com/models [accessed March 19, 2015].
} 
times. PHEV operators can rely on the gasoline drive in the event they deplete the vehicle's battery (and for comparison to the energy transfer of the charge rate, the energy being added by the gasoline pump is about $10 \mathrm{MW})$. At present, no PHEV on the market or near commercialization has DC charging capability (although the upcoming Mitsubishi Outlander PHEV may offer DC charging capability as an option).

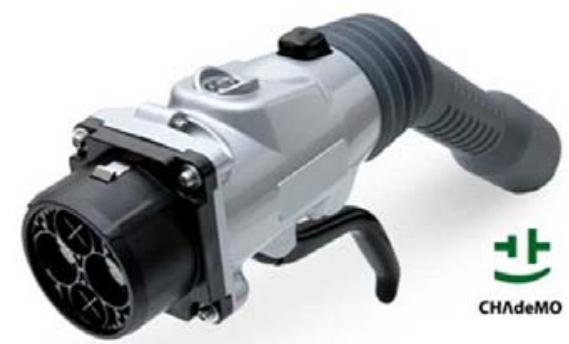

Figure 9. CHAdeMO-compliant connector. ${ }^{25}$

Because the battery of a BEV is typically much larger than that of a PHEV, recharge times are longer (see Figure 10). BEVs that see daily mileage near the limits of the advertised range do better when recharged using AC Level 2 EVSE or DCFC, because AC Level 1 recharge times are usually extensive. PHEVs, on the other hand, generally can use AC Level 1 EVSE for overnight charging to ensure a fully charged battery at the start of daily use. AC Level 2 EVSE units provide greater range in the shortest amount of time when intermediate or opportunity charging. DCFC provides the fastest recharge capability for those vehicles equipped with DCFC inlets.

Figure 10. Public AC Level 2 EVSE. ${ }^{26}$

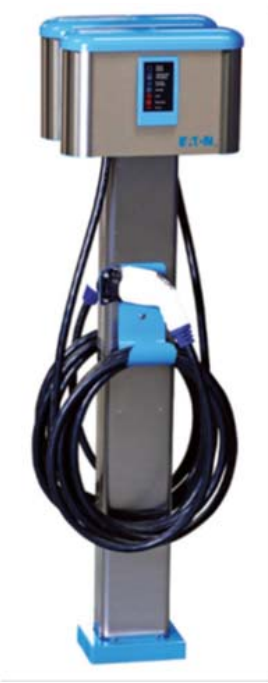

\subsubsection{Electric Vehicle Supply Equipment Stations}

AC Level 2 charging is the predominant rating of publicly accessible EVSE because of its wide acceptance by auto manufacturers and recharge times that are faster than AC Level 1 charging. Purchase and installation costs are more manageable than DCFCs and less space is required. Several manufacturers of AC Level 2 equipment exist and the agency should review brands for comparison purposes. Figure 10 provides an example of a public AC Level 2 EVSE unit.

DCFCs also are available from several manufacturers. Figure 11 illustrates one such charger. This particular charger uses the CHAdeMO connector standard.

\footnotetext{
${ }^{25}$ https://radio.azpm.org/p/azspot/2012/5/10/1632-electric-cars/ [accessed March 16, 2015]

${ }^{26}$ http://www.eaton.com/ecm/groups/public/@pub/@electrical/documents/content/pa00401002e.pdf/ [accessed March 16, 2015]
} 


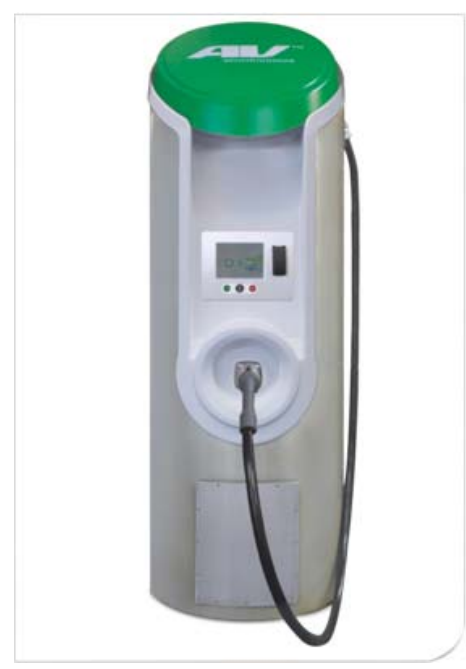

Figure 11. Public DCFC unit. ${ }^{27}$

In general, installation costs are higher for DCFC because of the higher voltage requirements and the inclusion of an $\mathrm{AC}$ to DC converter and other safety and design features. Costs for both types are highly dependent on site characteristics such as distance to the nearest power source, asphalt or concrete cutting and repair, conduit requirements, and payment systems, if any.

Payment and equipment control systems included by some suppliers provide the potential for use by privately owned vehicles for a fee, but can allow agency fleet vehicle use without direct payment. These systems also allow for accurate record keeping of vehicle charging requirements.

\section{NATIONAL AGENCIES MISSION ANALYSIS}

\subsection{Analyzed Fleet Summary}

This study selected 162 vehicles for monitoring. Heavy-duty trucks, buses, and specialty vehicles were removed from the summary because no production PEVs are available for replacement or, if available, specific replacement and charging analysis would be required. Meaningful results are available on 153 of the monitored vehicles. Table 9 lists the vehicles for each agency by EPA class.

Table 9. Study fleet vehicles.

\begin{tabular}{lccccccccc}
\hline & $\begin{array}{c}\text { Sedan } \\
\text { Compact }\end{array}$ & $\begin{array}{c}\text { Sedan } \\
\text { Midsize }\end{array}$ & $\begin{array}{c}\text { Sedan } \\
\text { Large }\end{array}$ & SUV & $\begin{array}{c}\text { Mini- } \\
\text { Van }\end{array}$ & $\begin{array}{c}\text { Cargo } \\
\text { Van }\end{array}$ & Pass Van & Pickup & Total \\
\hline GGNRA & - & - & 2 & 7 & - & - & - & 5 & 14 \\
FVNHS & - & - & - & - & 1 & - & - & 1 & 2 \\
GCNP & 1 & - & 1 & 5 & 1 & - & - & 3 & 11 \\
RMNP & - & - & - & 5 & - & - & - & 3 & 8 \\
SLBE & - & - & 1 & 1 & - & 1 & - & 9 & 12 \\
CTNF & - & - & 1 & 2 & - & - & - & 9 & 12 \\
WSTF & - & - & - & 2 & 2 & - & - & 6 & 10 \\
GRC & - & 6 & - & - & - & - & - & 3 & 9 \\
SSP & - & 1 & 2 & 2 & 3 & 1 & - & 2 & 11 \\
USCG & 4 & 1 & 1 & - & 4 & - & - & - & 10 \\
ASPR & - & - & - & 2 & - & - & - & 3 & 5 \\
VA-BR & 2 & 2 & 1 & - & 1 & - & 3 & - & 9 \\
\hline
\end{tabular}

${ }^{27}$ http://evsolutions.avinc.com/products/public_charging/public_charging_b $[$ March 16, 2015] 


\begin{tabular}{lccccccccc}
\hline & $\begin{array}{c}\text { Sedan } \\
\text { Compact }\end{array}$ & $\begin{array}{c}\text { Sedan } \\
\text { Midsize }\end{array}$ & $\begin{array}{c}\text { Sedan } \\
\text { Large }\end{array}$ & SUV & $\begin{array}{c}\text { Mini- } \\
\text { Van }\end{array}$ & $\begin{array}{c}\text { Cargo } \\
\text { Van }\end{array}$ & Pass Van & Pickup & Total \\
\hline VA-MAN & 3 & 2 & 1 & - & 1 & - & 2 & - & 9 \\
NIH & - & - & 6 & 6 & 3 & 1 & - & 3 & 19 \\
INL & 2 & - & - & 2 & 1 & - & 2 & 5 & 12 \\
Total & 12 & 12 & 16 & 34 & 17 & 3 & 7 & 52 & 153 \\
\hline
\end{tabular}

Figure 12 shows the relative composition of all vehicles analyzed. High reliance on pickup trucks and sport utility vehicles (SUVs) as the most versatile of vehicles is evident.
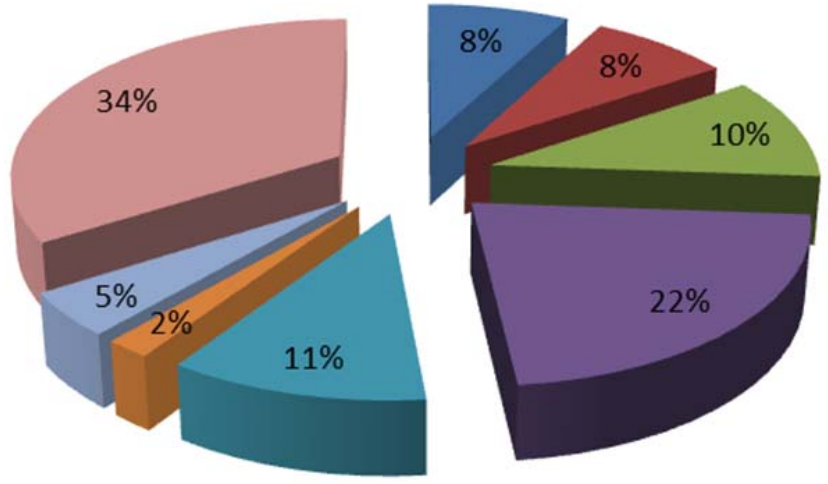

- Sedan - Compact
- Sedan - Midsize
- Sedan - Large
- SUV
- Minivan
- Van - Cargo
- Van - Pass
- Pickup

Figure 12. Composition of agencies' monitored fleets.

The selection of vehicles for monitoring intended to be a representative sample of the full fleet of vehicles in order to provide the possibility of extrapolating results to the full fleet. The composition of monitored vehicle types compared to available full fleet information is shown in Figure 13.

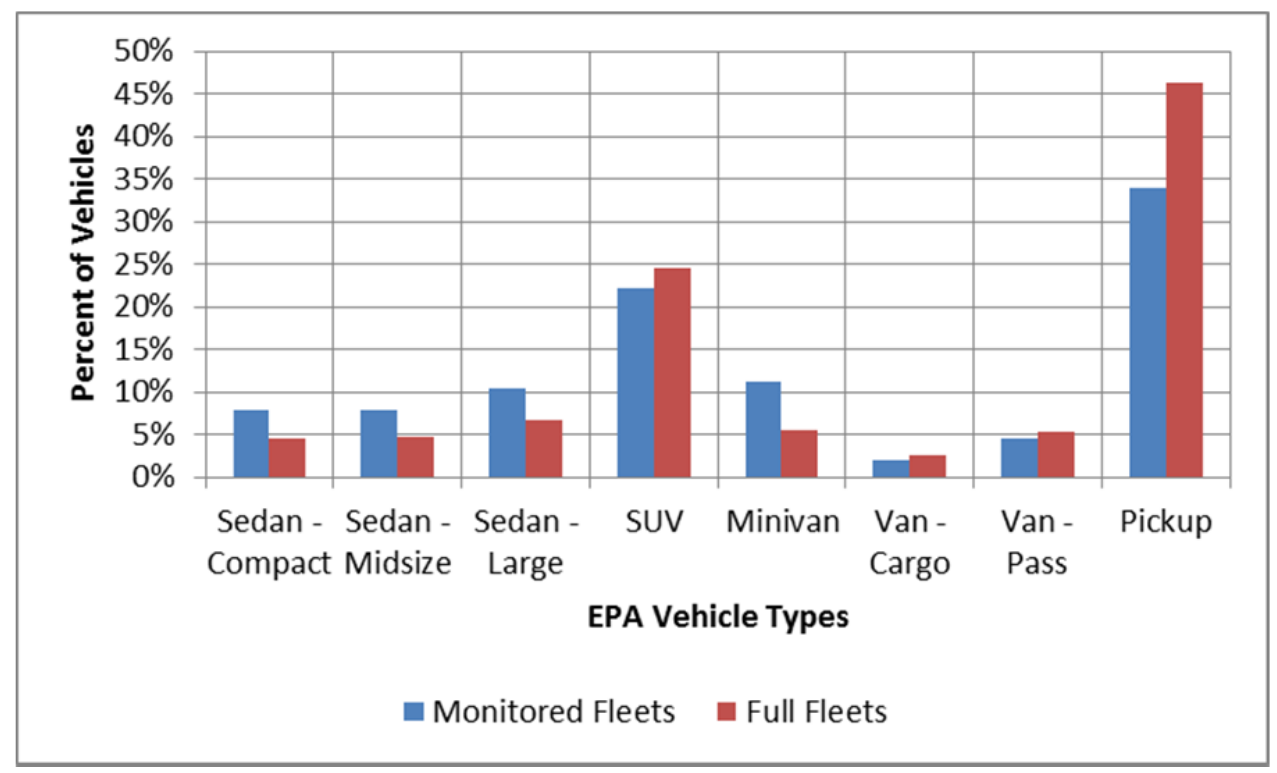

Figure 13. Comparison of monitored vehicles types versus full fleet vehicle types.

As displayed, the monitored vehicles fairly represent the full fleet, although the figure slightly emphasizes sedans and minivans. PEV sedan models are more generally available as vehicle replacements and are currently the only PEV vehicle type available on the GSA list. Note that certain vehicle types, such as low-speed vehicles, heavy-duty trucks, buses, specialty vehicles, forklifts, and non-powered equipment were not analyzed. Based on the agencies' inputs on fleet vehicles, an assessment of mission by vehicle type was completed. Table 10 shows the results of that assessment. 
Table 10. Study fleet mission assessment.

\begin{tabular}{lccccccccc} 
& $\begin{array}{c}\text { Sedan } \\
\text { Compact }\end{array}$ & $\begin{array}{c}\text { Sedan } \\
\text { Midsize }\end{array}$ & $\begin{array}{c}\text { Sedan } \\
\text { Large }\end{array}$ & SUV & $\begin{array}{c}\text { Mini- } \\
\text { Van }\end{array}$ & $\begin{array}{c}\text { Cargo } \\
\text { Van }\end{array}$ & Pass Van & Pickup & Total \\
\hline Pool & 9 & 10 & 9 & 11 & 9 & - & 4 & 10 & 62 \\
Support & 3 & - & 1 & 11 & 7 & 3 & 3 & 38 & 66 \\
Enforcement & - & 2 & 6 & 11 & - & - & - & 3 & 22 \\
Transport & - & - & - & 1 & 1 & - & - & 1 & 3 \\
Total & 12 & 12 & 16 & 34 & 17 & 3 & 7 & 52 & 153 \\
\hline
\end{tabular}

The vehicle types used in the mission assignments monitored are shown in Figure 14. For example, $57 \%$ of all pickup trucks monitored were used in the support mission and $47 \%$ of SUVs monitored were involved in enforcement activities.

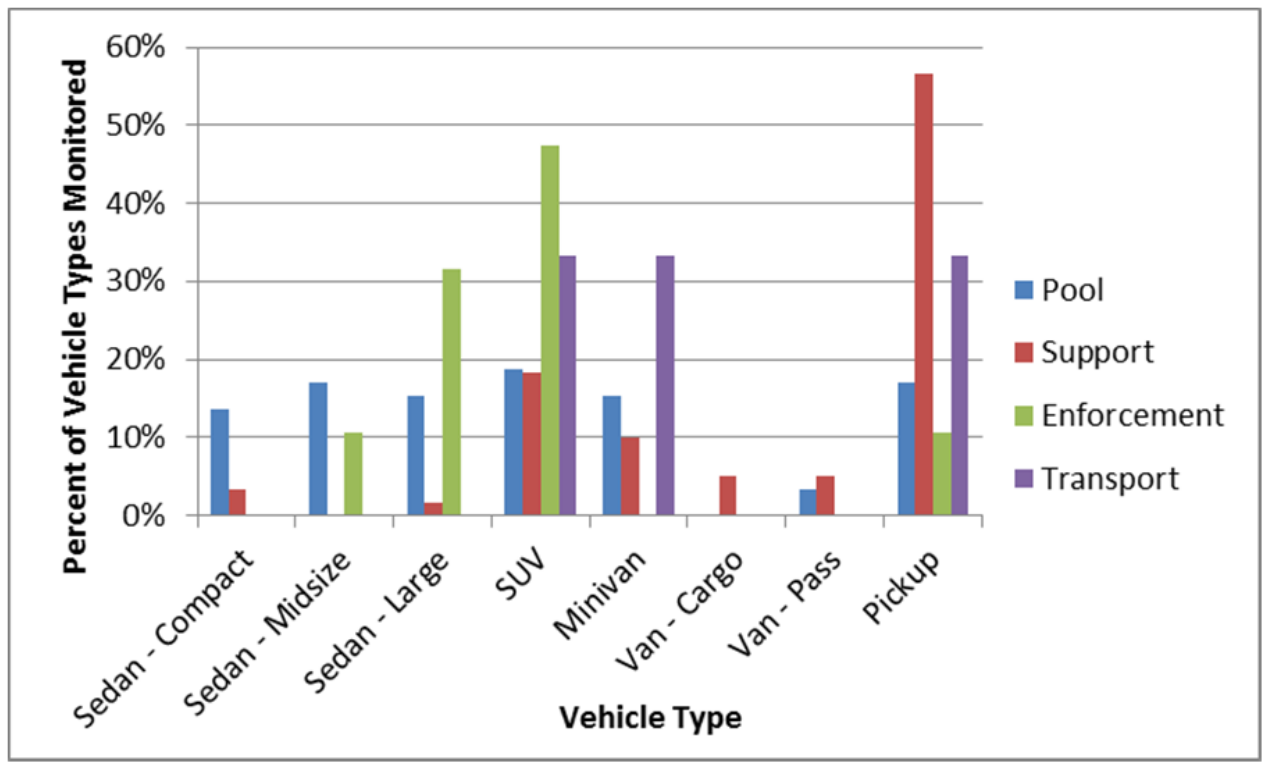

Figure 14. Vehicle type by mission.

The selection of vehicles for monitoring intended to be a representative sample of the full fleet of vehicles in the mission assigned. Mission assignments of monitored vehicle types compared to available full fleet information are shown in Figure 15. As displayed, monitored vehicles fairly represent the full fleet.

Data collection took place from August 2011 through March 2015. Vehicle data sheets (presented in each agency's report) detail the collected data and individual analysis for each vehicle.

Of the data collected, validation occurred for $97.9 \%$ of the total collection, while null values exist for the balance. Table 11 shows this information by mission type.

Trips and outings were described in Section 3.3. Aside from specific vehicle cargo requirements, these factors are the most important in determining the ability of BEVs and PHEVs to replace their ICE vehicle counterparts. A BEV driver must be able to complete the mission within the range capability of the BEV, which is typically defined by an outing (i.e., all trips away from and back to the vehicle's home base). If charging stations are available at more locations, the length of the trip to that location becomes important. The total of all daily travel is also important because if all daily travel is within the range capability of the $\mathrm{BEV}$, charging may be accomplished once per day when the vehicle is idle. PHEVs do not have the same range limitations, but daily travel is important for calculations of fuel and GHG emissions reductions.

Figure 16 shows the cumulative percent of vehicle daily travel for all monitored vehicles. Fully $84 \%$ of all vehicles traveled less than an average of 70 miles per day, which is the typical range for BEVs.

Considering the peak travel days, $34 \%$ of all monitored vehicles traveled less than the average of 70 miles 
per day. Without consideration of any other factors, the fleet could consist of $34 \%$ BEVs and $16 \%$ PHEVs with the balance a mix of the two types. The highest recorded daily travel typically involved long excursions away from the home base and may have occurred during multi-day events.

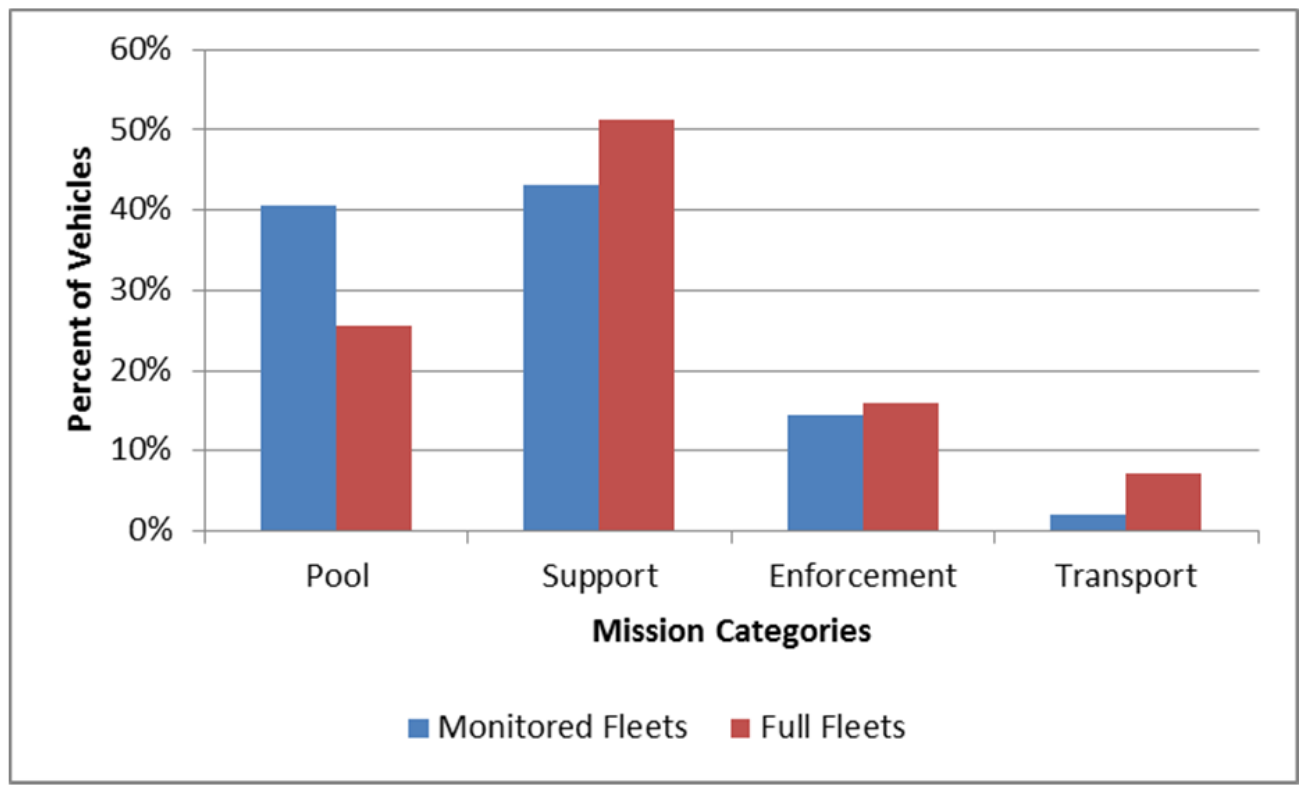

Figure 15. Mission comparison of monitored vehicles to the full fleet of vehicles.

Table 11. Vehicle data logger reporting summary.

\begin{tabular}{lccc}
\hline \multicolumn{4}{c}{ Vehicle Data Logger Reporting Summary } \\
Mission & \% Collected & \% Null Values & Total \\
\hline Pool & 98.0 & 2.0 & $100 \%$ \\
Support & 97.9 & 2.1 & $100 \%$ \\
Enforcement & 97.5 & 2.5 & $100 \%$ \\
Transport & 99.3 & 0.7 & $100 \%$ \\
All Vehicles & 97.9 & 2.1 & $100 \%$ \\
\hline
\end{tabular}

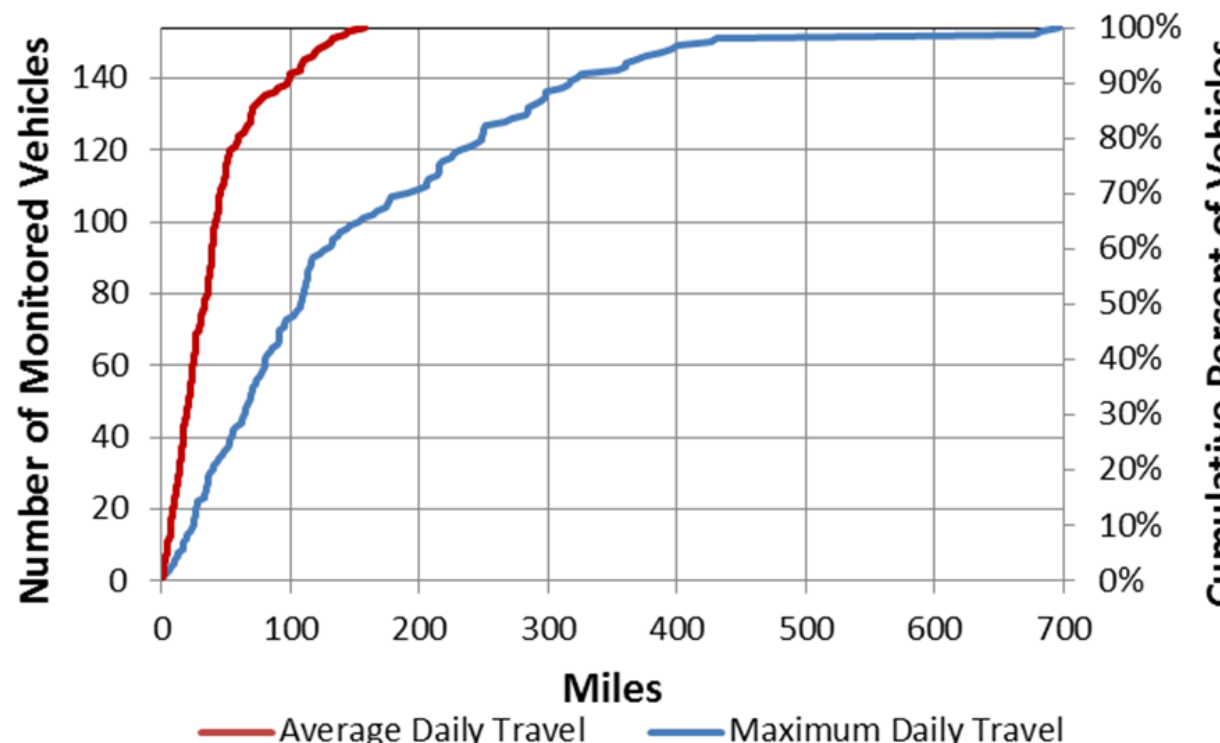

Figure 16. Average and maximum daily travel for monitored vehicles. 
Also of interest, $61 \%$ of the vehicles monitored traveled less than an average of 40 miles per day. PHEVs replacing these vehicles could, depending on the particular model, typically operate in CD mode for the entire day and yet be available for assignments that exceed that at any time.

Figure 17 displays the cumulative percent of vehicle outings for both their average length and their maximum length.
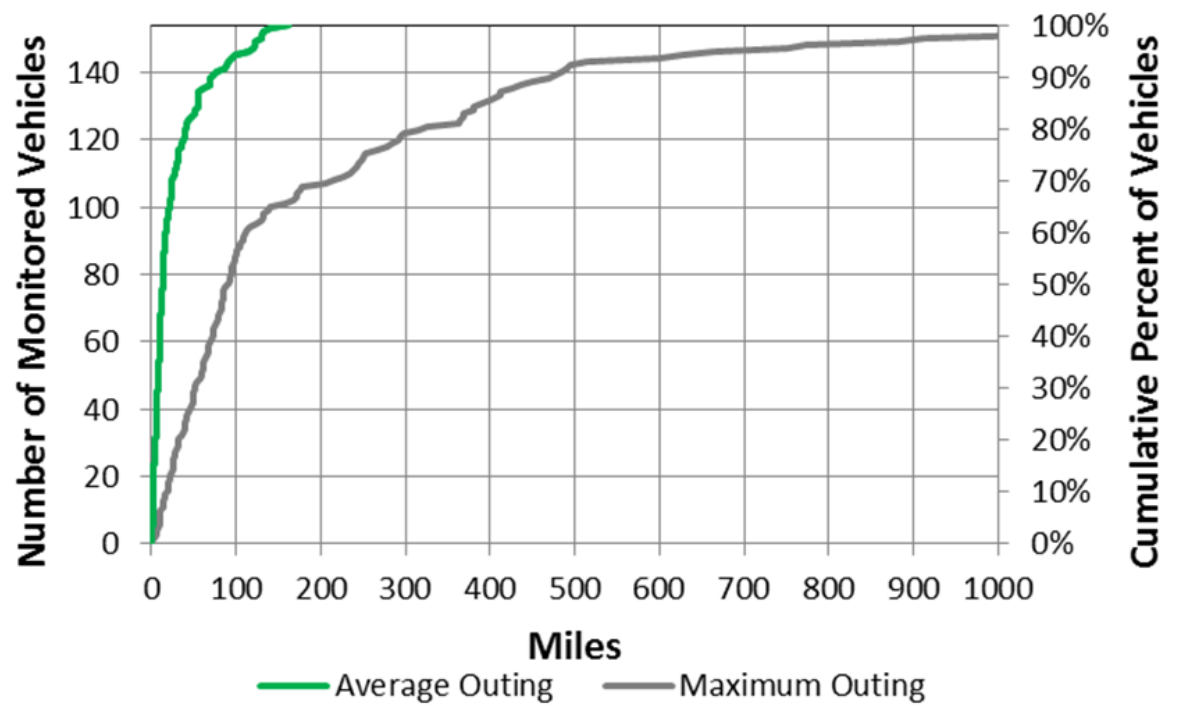

Figure 17. Average and maximum outings for monitored vehicles.

The longest outing recorded was 1,919 miles. The four outings exceeding 1,000 miles are not shown in Figure 17 for clarity of scale. Outings become important if there is sufficient time for recharging between outings. In this manner, a BEV could complete an outing, recharge, and be available for another outing. Considering these outings, $90 \%$ of the vehicles averaged less than 70 miles, making them suitable for BEV replacement. In addition, 39\% of the vehicles had maximum outings less than 70 miles.

Agencies select the type of vehicle based on the mission they require the vehicle to perform. Thus, conducting analysis by mission is of more value than conducting analysis by vehicle type.

\subsection{Pool Vehicle Mission Analysis}

\subsubsection{General Vehicle Information}

Pool vehicles are typically light-duty motor vehicles for use in passenger transportation, with not more than 10 passengers. Pool missions can vary by agency, location, and jurisdiction; however, they typically utilize sedans, minivans, SUVs, vans, or small pickup trucks and typically do not carry specific cargo or equipment. Table 10 identifies the 62 pool vehicles monitored.

Incorporation of BEVs and/or PHEVs into the pool mission is a definite possibility. Pool vehicles used for shorter trips or outings qualify for BEV or PHEV replacement, while other pool vehicle activities associated with longer trips may require PHEV capabilities.

\subsubsection{Summary for Pool Vehicles}

This section aggregates data for all pool vehicles monitored. Table 12 summarizes pool travel during the study period for those days when the vehicle was driven. The vehicles were driven 95,418 miles, logged 4,430 hours, and idled for 999 hours during the study period. 
Table 12. Pool vehicles travel summary.

\begin{tabular}{lcccc}
\hline & Pool Vehicles Travel Summary & & \\
& $\begin{array}{c}\text { Per Day } \\
\text { Average/Peak }\end{array}$ & $\begin{array}{c}\text { Per Outing } \\
\text { Average/Peak }\end{array}$ & $\begin{array}{c}\text { Per Trip } \\
\text { Average/Peak }\end{array}$ & Total \\
\hline Travel Distance (Miles) & $38.4 / 682.9$ & $27.9 / 1,368.7$ & $7.5 / 268.8$ & 95,418 \\
Travel Time (Minutes) & $94.0 / 713.0$ & $60.7 / 1,681.0$ & $17.1 / 362.0$ & 265,826 \\
Idle Time (Minutes) & $19.1 / \mathrm{NA}$ & $11.4 / \mathrm{NA}$ & $3.5 / \mathrm{NA}$ & 59,930 \\
\hline
\end{tabular}

\subsubsection{Pool Vehicles Daily Summary}

When driven, the average travel distance per day for pool vehicles was 38.4 miles. Figure 18 identifies the daily travel average and maximum distances for all pool vehicles monitored. Fully $90 \%$ of pool vehicles travel was an average of less than 70 miles per day. Meanwhile, $26 \%$ of pool vehicles travel was less than 70 miles on their peak travel days. Therefore, at least $26 \%$ of the pool fleet could consist of BEVs without considering any additional charging activities throughout the day.
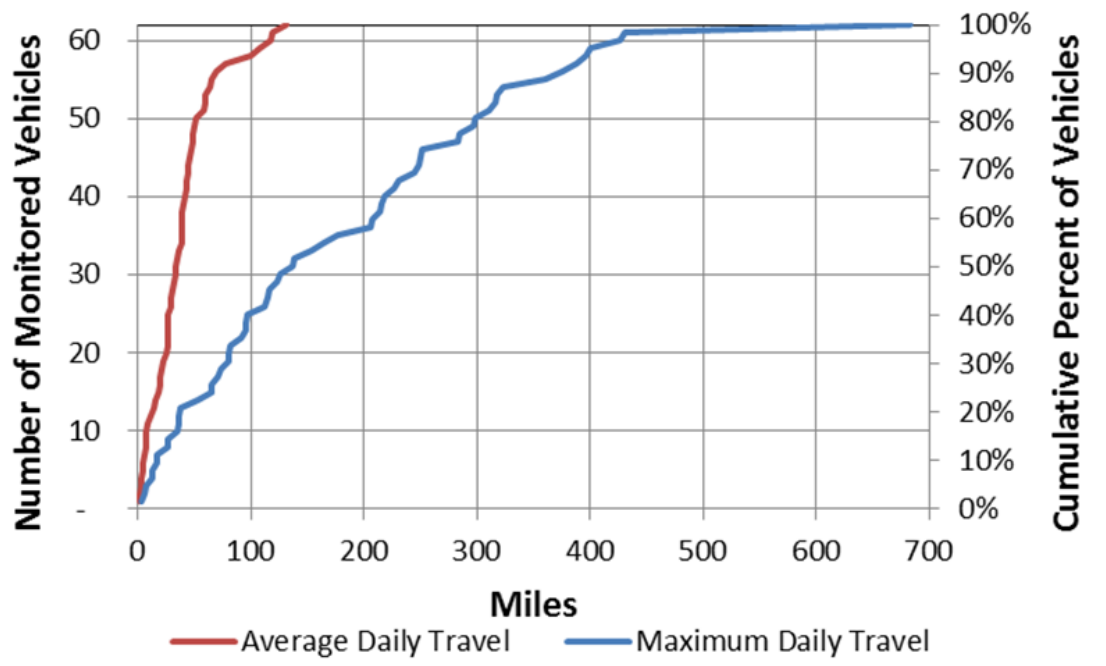

Figure 18. Pool vehicle average and maximum daily travel miles (all vehicles).

Figure 19 shows the average and maximum outing distances traveled for all monitored pool vehicles.

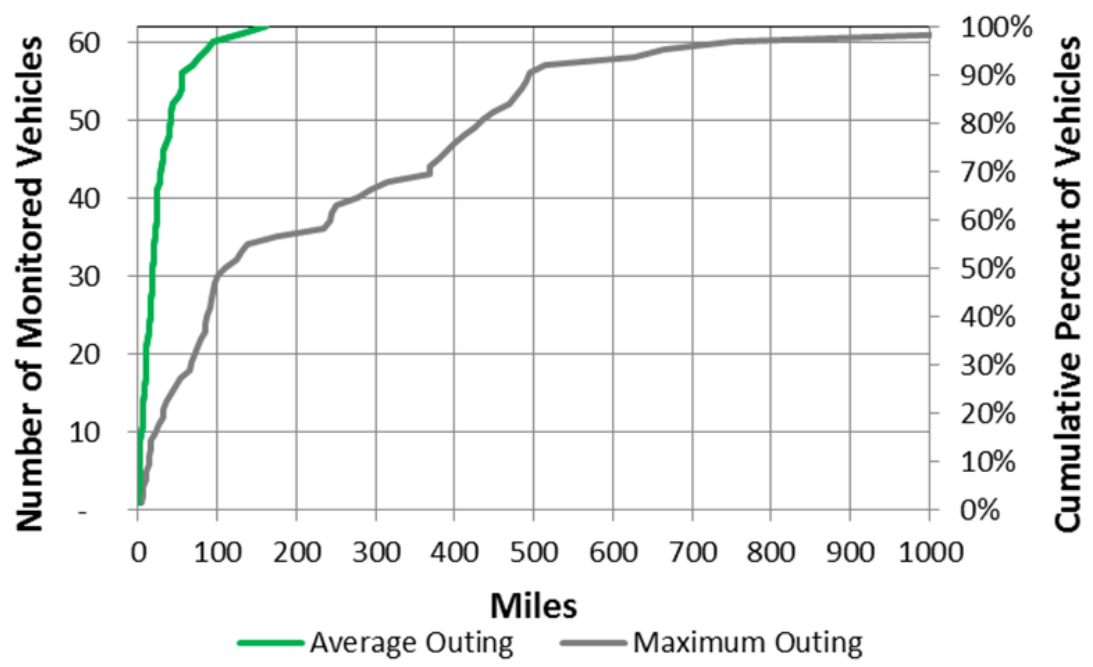

Figure 19. Pool vehicle average and maximum outing travel miles (all vehicles). 
The average travel outing for pool vehicles was 27.9 miles. Fully $92 \%$ of all pool vehicle average outings were less than 70 miles. Thus, $92 \%$ of pool vehicles could be BEVs if sufficient recharge time was available for additional outings. The two outings exceeding 1,000 miles were not shown for clarity of scale.

\subsubsection{Pool Vehicle Observations/Summary}

For any agency's pool fleet of vehicles, a mix of BEVs and PHEVs would appear to meet all mission objectives without consideration of specific cargo requirements. The pool mission typically does not include cargo capabilities, but BEVs capable of carrying significant cargo are available.

PHEVs can accomplish the same mission as the current fleet when only considering travel times and distances because of the CS mode capabilities of PHEVs. Figure 18 shows that $63 \%$ of all pool vehicles travelled less than 40 miles per day, which typically is the maximum distance a PHEV will travel in CD mode. This represents a significant operating cost savings opportunity, while retaining the ability to go longer distances when needed. In addition, $77 \%$ of the outings were less than 40 miles and could be completed in CD mode for certain PHEVs if the battery was fully charged prior to the outing.

Meanwhile, $90 \%$ of the vehicles operated with an average daily travel within the typical capability of a BEV and $96 \%$ of the vehicles had average outings in this capability.

A fleet of pool vehicles consisting of at least $26 \%$ BEVs could conservatively meet all mission requirements because all maximum daily travel was within the capabilities of the BEV. The balance of the pool fleet of $74 \%$ PHEVs then provides a very conservative composition.

A more managed pool fleet could increase the percentage of BEVs and ensure that, with assignment of vehicles, the planned trip is considered when assigning a BEV or PHEV. For the monitored fleet of pool vehicles, the individual agencies' reports show 32 (52\%) BEVs and $30(48 \%)$ PHEVs.

The agencies reported 368 total vehicles in all the fleets with the pool mission. The agencies' reports suggest that 161 (44\%) BEVs and 207 (56\%) PHEVs conservatively meet pool vehicle travel requirements.

\subsubsection{Pool Vehicle Types}

The monitoring pool vehicles consisted of the types of vehicles identified in Figure 20.

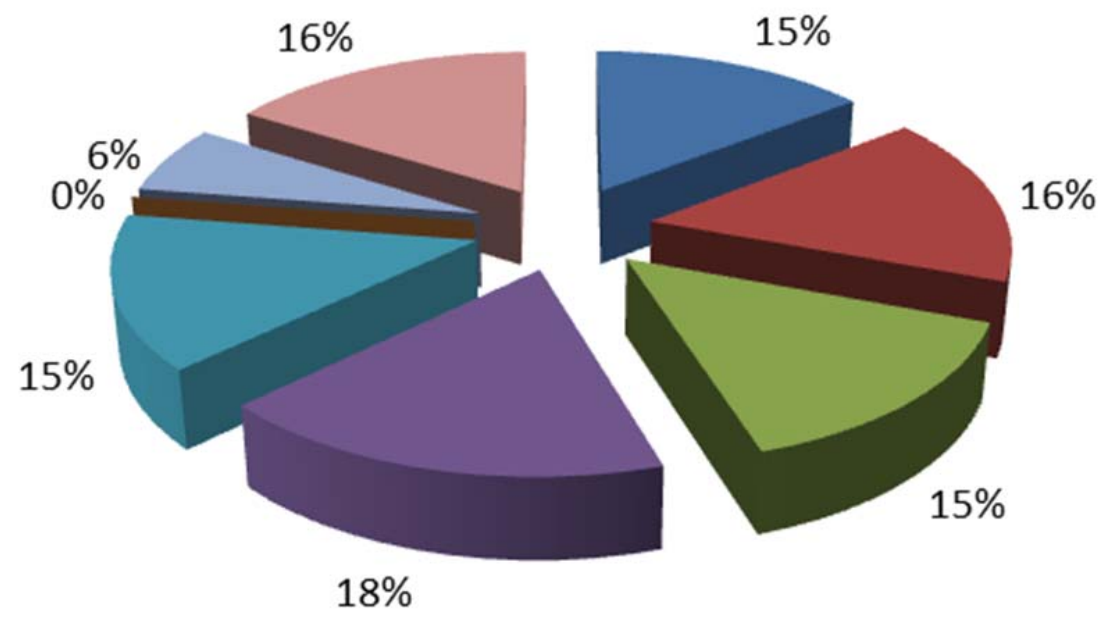

Sedan - Compact
Sedan - Midsize
Sedan - Large
SUV
Minivan
Van - Cargo
Van - Pass
Pickup

Figure 20. Monitored pool vehicle types.

Equal proportions of each vehicle type, other than passenger and cargo vans, were represented in the pool fleets. 


\subsection{Support Vehicles Evaluation}

\subsubsection{General Vehicle Information}

Support vehicles provide a specific work function, facilitating the mission of a particular group. The vehicles are generally SUVs, minivans, or light-duty pickup trucks and may contain aftermarket modifications to support the mission. While typically assigned to maintenance and service functions, operations may vary depending on agency needs. Table 10 identifies the 66 support vehicles monitored.

Incorporation of BEVs and/or PHEVs into the support mission is a definite possibility. Support vehicles used for shorter trips or outings qualify for BEV or PHEV replacement, while other support vehicle activities that are associated with longer trips may require PHEV capabilities.

\subsubsection{Summary for Support Vehicles}

This section aggregates data for all support vehicles monitored. Table 13 summarizes support travel during the study period for those days when the vehicle was driven. The vehicles were driven 92,451 miles, logged 4,800 hours, and idled for 1,263 hours during the study period.

Table 13. Support vehicles travel summary.

\begin{tabular}{|c|c|c|c|c|}
\hline \multicolumn{5}{|c|}{ Support Vehicles Travel Summary } \\
\hline & $\begin{array}{c}\text { Per Day } \\
\text { Average/Peak }\end{array}$ & $\begin{array}{c}\text { Per Outing } \\
\text { Average/Peak }\end{array}$ & $\begin{array}{c}\text { Per Trip } \\
\text { Average/Peak }\end{array}$ & Total \\
\hline Travel Distance (Miles) & $44.4 / 696.8$ & $29.1 / 1,919.7$ & $7.3 / 220.6$ & 92,451 \\
\hline Travel Time (Minutes) & 123.6/796.0 & $67.2 / 3,151.0$ & $19.2 / 458.0$ & 287,989 \\
\hline Idle Time (Minutes) & $31.4 / \mathrm{NA}$ & $15.4 / \mathrm{NA}$ & 4.8/NA & 75,807 \\
\hline
\end{tabular}

\subsubsection{Support Vehicles Daily Summary}

When driven, the average travel distance per day for support vehicles was 44.4 miles. Figure 21 identifies the daily travel average and maximum distances for all the support vehicles monitored. Fully $79 \%$ of support vehicles travelled an average of less than 70 miles per day. In addition, $41 \%$ of support vehicles travelled less than 70 miles on their peak travel days. Therefore, at least $41 \%$ of the support fleet could consist of BEVs without considering any additional charging activities throughout the day.

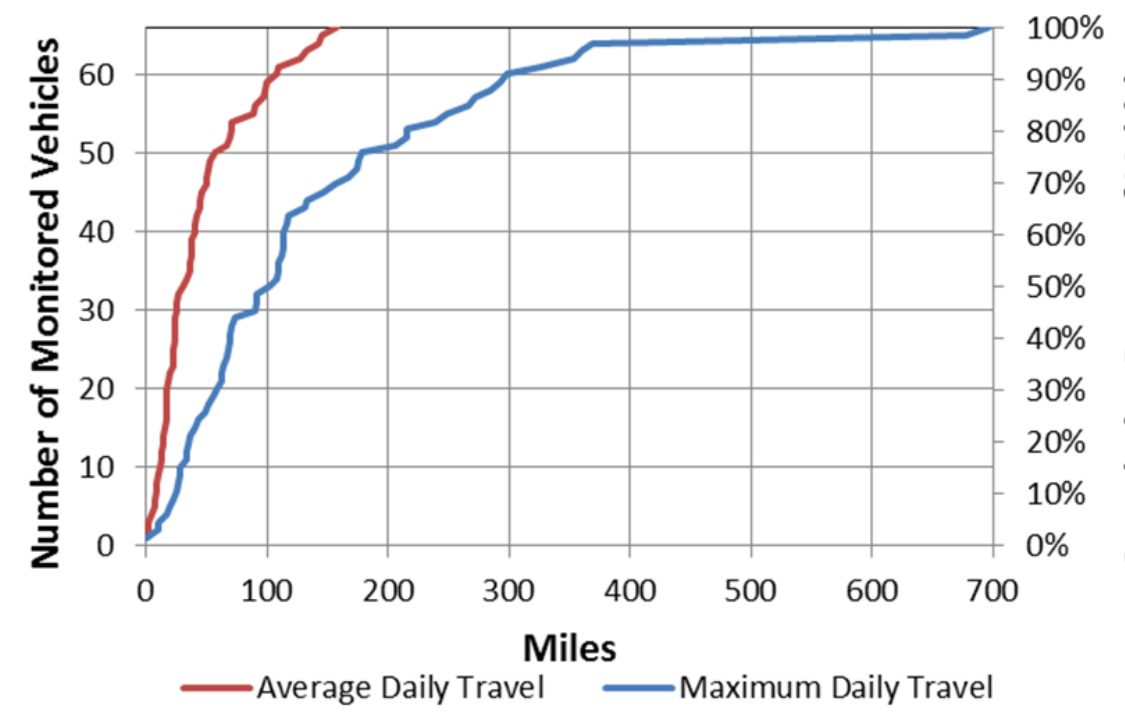

Figure 21. Support vehicle average and maximum daily travel miles (all vehicles). 
Figure 22 shows the average and maximum outing distances traveled for all monitored support vehicles.
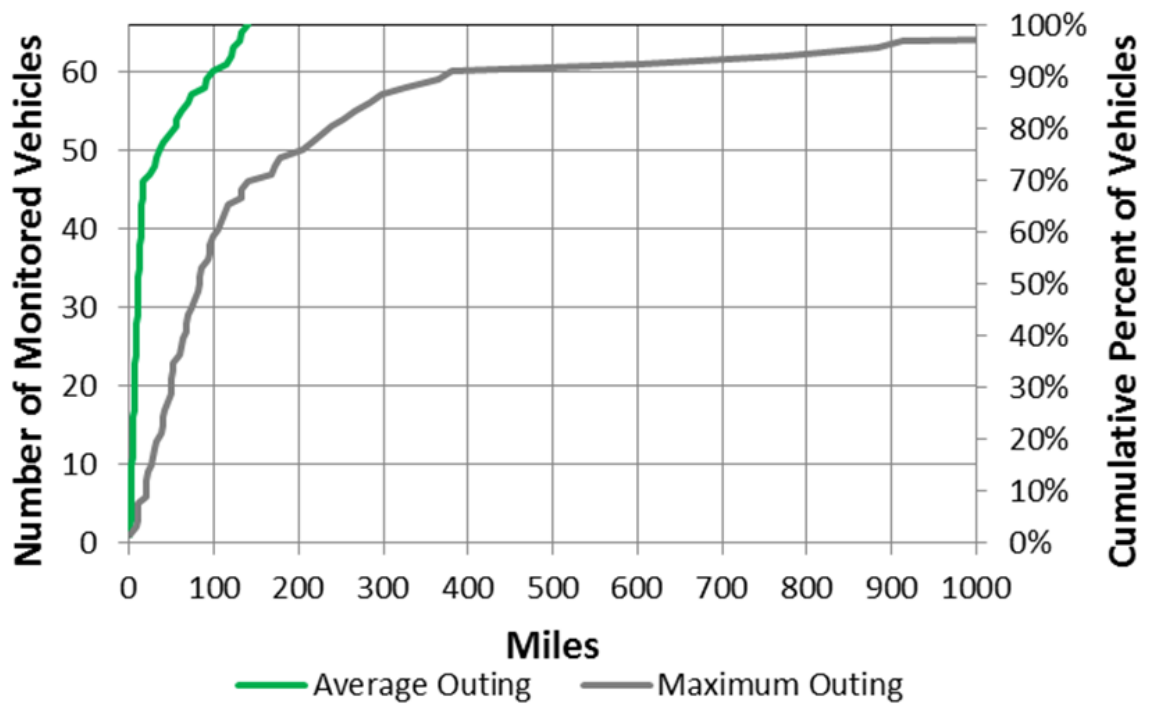

Figure 22. Support vehicle average and maximum daily outing miles (all vehicles).

The average travel outing for support vehicles was 29.1 miles. Fully $85 \%$ of all support vehicle average outings were less than 70 miles. Thus, $85 \%$ of support vehicles could be BEVs if sufficient recharge time is available for additional outings. The two outings of 1,562 and 1,919 miles were not shown for clarity of scale.

\subsubsection{Support Vehicle Observations/Summary}

For any agency's support fleet of vehicles, a mix of BEVs and PHEVs would appear to meet all mission objectives without consideration of specific cargo requirements. The support mission may include cargo capabilities and BEVs capable of carrying significant cargo.

PHEV can accomplish the same mission as the current fleet when only considering travel times and distances because of the CS mode capabilities of PHEVs. Figure 21 shows that $59 \%$ of all support vehicles travel less than 40 miles per day, which typically is the maximum distance a PHEV will travel in CD mode. This represents a significant operating cost savings opportunity, while retaining the ability to go longer distances when needed. In addition, $77 \%$ of the outings were less than 40 miles and could be completed in CD mode for certain PHEVs if the battery was fully charged prior to the outing.

Meanwhile, $79 \%$ of the vehicles operated with an average daily travel within the typical capability of a BEV and $85 \%$ of the vehicles had average outings in this capability.

A fleet of support vehicles consisting of at least $41 \%$ BEVs could conservatively meet all mission requirements because all maximum daily travel was within the capabilities of the BEV. The balance of the support fleet of 59\% PHEVs then provided a very conservative composition.

A more managed support fleet could increase the percentage of BEVs and ensure that, with assignment of vehicles, the planned trip is considered in assigning a BEV or PHEV. For the monitored fleet of support vehicles, the individual agencies' reports show 32 (52\%) BEVs and 29 (48\%) PHEVs.

The agencies reported 868 total vehicles in all the fleets of appropriate vehicle types with the support mission. The agencies' reports suggest that 439 (51\%) BEVs and 429 (49\%) PHEVs conservatively meet vehicle travel requirements.

\subsubsection{Support Vehicle Types}

The monitored support vehicles consist of the types of vehicles identified in Figure 23. Strong reliance on pickup trucks is evident. 


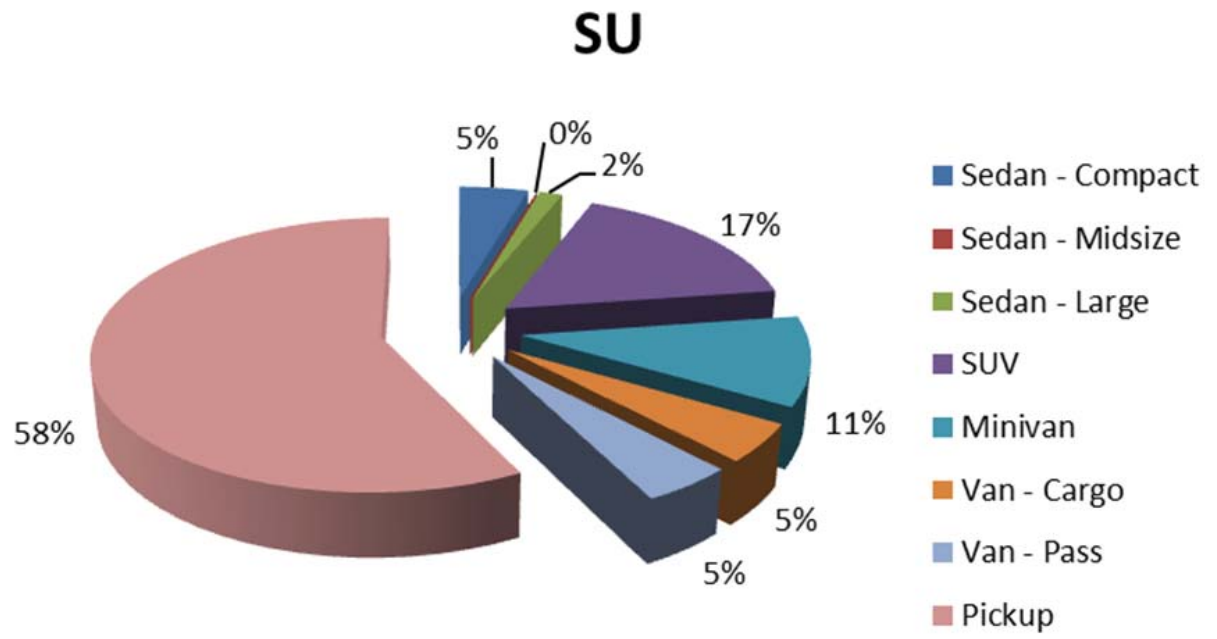

Figure 23. Monitored support vehicle types.

\subsection{Enforcement Vehicles Evaluation}

\subsubsection{General Vehicle Information}

Enforcement vehicles are typically light-duty motor vehicles specifically approved in an agency's appropriation act for use in apprehension, surveillance, police, or other law enforcement work. Enforcement missions can vary by agency, location, and jurisdiction; however, they typically utilize sedans, minivans, vans, or small pickup trucks and typically do not carry specific cargo or equipment. Table 10 identifies the 22 enforcement vehicles monitored.

Incorporation of BEVs and/or PHEVs into the enforcement mission is a definite possibility. Enforcement fleet managers typically do not find vehicles with range limitations suitable for all mission requirements, but certain activities, such as administration and parking enforcement, can be met by BEVs. In addition, vehicles used for shorter trips or outings qualify for BEV or PHEV replacement, while other enforcement vehicle activities associated with longer trips may require PHEV capabilities.

\subsubsection{Summary for Enforcement Vehicles}

This section aggregates data for all enforcement vehicles monitored. Table 14 summarizes enforcement travel during the study period for those days when the vehicle was driven. The vehicles were driven 37,556 miles, logged 3,252 hours, and idled for 1,182 hours during the study period.

Table 14. Enforcement vehicles travel summary.

\begin{tabular}{lcccc}
\hline \multicolumn{5}{c}{ Enforcement Vehicles Travel Summary } \\
& $\begin{array}{c}\text { Per Day } \\
\text { Average/Peak }\end{array}$ & $\begin{array}{c}\text { Per Outing } \\
\text { Average/Peak }\end{array}$ & $\begin{array}{c}\text { Per Trip } \\
\text { Average/Peak }\end{array}$ & Total \\
\hline Travel Distance (Miles) & $43.4 / 121.9$ & $23.1 / 122.3$ & $5.1 / 17.5$ & 37,556 \\
Travel Time (Minutes) & $203.1 / 635.4$ & $635.4 / 100.3$ & $20.6 / 41.7$ & 195,135 \\
Idle Time (Minutes) & $69.3 / \mathrm{NA}$ & $37.4 / \mathrm{NA}$ & $7.0 / \mathrm{NA}$ & 70,909 \\
\hline
\end{tabular}

\subsubsection{Enforcement Vehicles Daily Summary}

When driven, the average travel distance per day for enforcement vehicles was 43.4 miles. Figure 24 identifies the daily travel average and maximum distances for all monitored enforcement vehicles. Fully $82 \%$ of enforcement vehicles travelled an average of less than 70 miles per day. In addition, $23 \%$ of 
enforcement vehicles travelled less than 70 miles on their peak travel days. Therefore, at least $23 \%$ of the enforcement fleet could consist of BEVs without considering any other mission requirements or additional charging activities throughout the day.

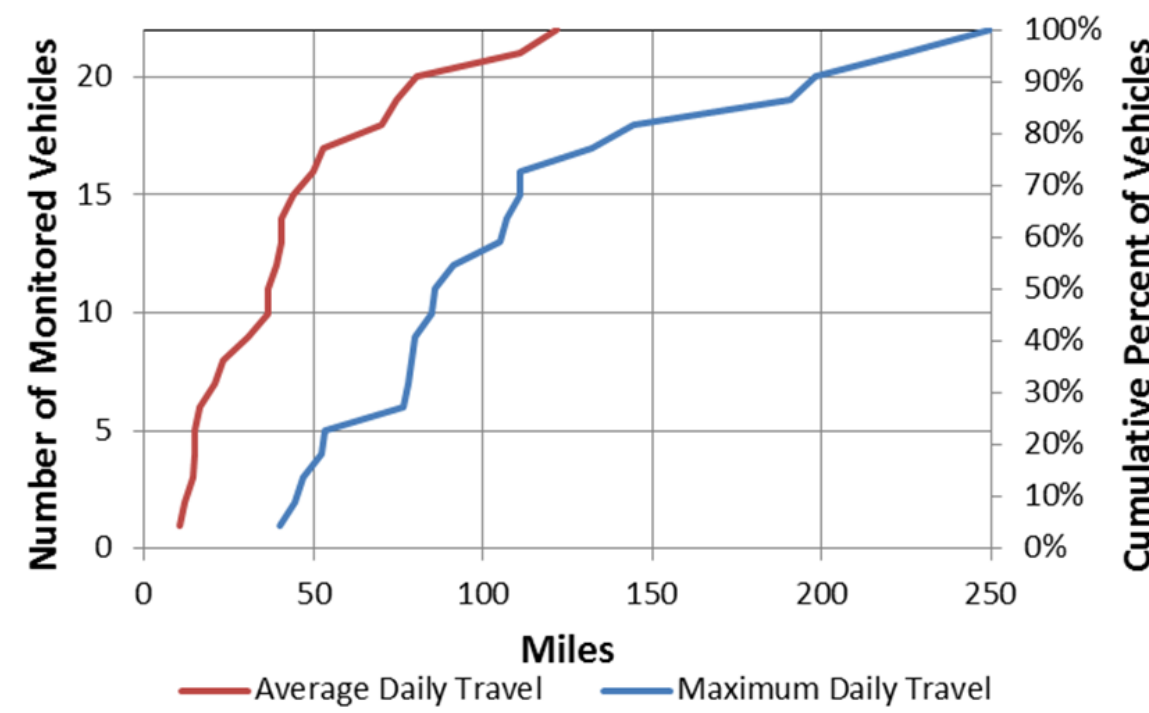

Figure 24. Enforcement vehicle average and maximum daily travel miles (all vehicles).

Figure 25 shows the average and maximum outing distances traveled for all monitored enforcement vehicles.

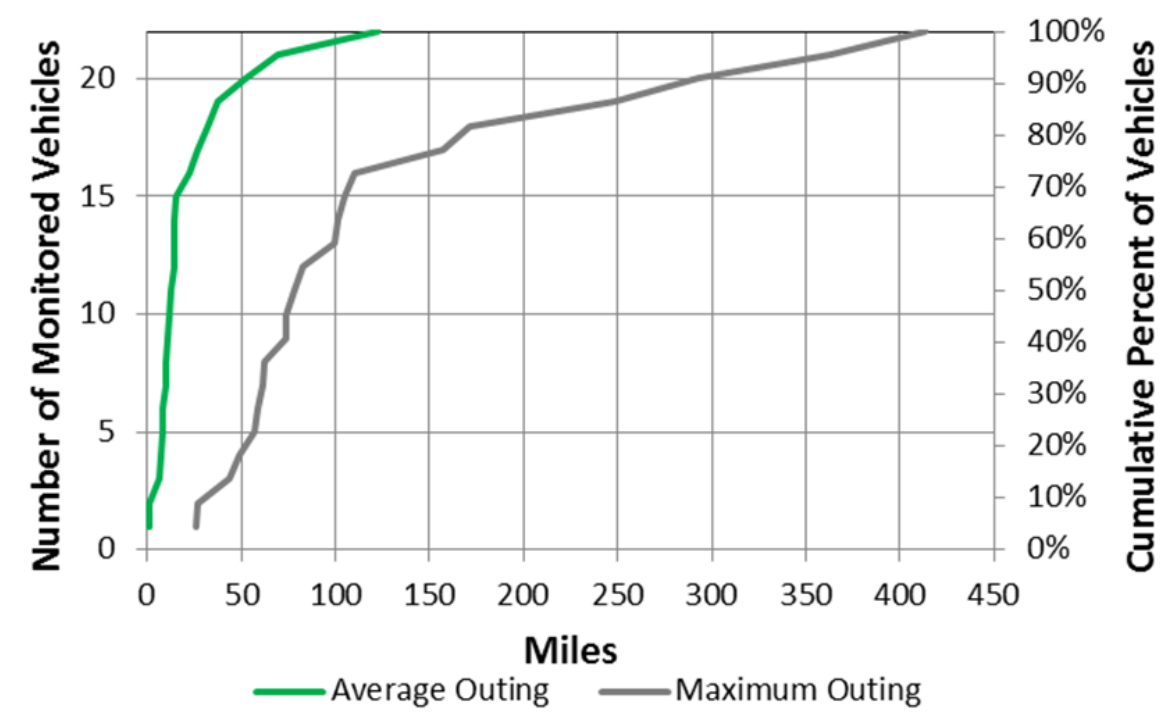

Figure 25. Enforcement vehicle average and maximum daily outing miles (all vehicles).

The average travel outing for enforcement vehicles was 23.1 miles. Fully $95 \%$ of all enforcement vehicle average outings were less than 70 miles. Thus, $95 \%$ of enforcement vehicles could be BEVs if sufficient recharge time was available for additional outings.

\subsubsection{Enforcement Vehicle Observations/Summary}

For any agency's enforcement fleet of vehicles, a mix of BEVs and PHEVs would appear to meet all mission objectives without consideration of specific cargo or other mission requirements. The enforcement mission typically does not include cargo capabilities, but BEVs capable of carrying significant cargo are available. 
PHEV can accomplish the same mission as the current fleet when only considering travel times and distances because of the CS mode capabilities of PHEVs. Figure 24 shows that $55 \%$ of all enforcement vehicles travel less than 40 miles per day, which typically is the maximum distance a PHEV will travel in CD mode. This represents a significant operating cost savings opportunity, while retaining the ability to go longer distances when needed. In addition, $86 \%$ of the outings were less than 40 miles and could be completed in CD mode for certain PHEVs if the battery was fully charged prior to the outing.

Meanwhile, $82 \%$ of the vehicles operated with an average daily travel within the typical capability of a BEV and $95 \%$ of the vehicles had average outings within this capability.

A fleet of enforcement vehicles consisting of at least $23 \%$ BEVs could conservatively meet all mission requirements because all maximum daily travel was within the capabilities of the BEV. The balance of the enforcement fleet with 77\% PHEVs provides a very conservative composition.

For the monitored fleet of enforcement vehicles, the individual agencies' reports show four $(18 \%)$ BEVs and 18 (82\%) PHEVs. This more conservative approach intended to provide more vehicles without range limitations, which resulted in the higher percentage of PHEVs. A more managed enforcement fleet could increase the percentage of BEVs and ensure that with assignment of vehicles, the planned trip is considered when assigning a BEV or PHEV.

The agencies reported 208 total vehicles in all fleets with the enforcement mission. The agencies' reports suggest that $81(39 \%)$ BEVs and 127 (61\%) PHEVs conservatively meet vehicle travel requirements.

\subsubsection{Enforcement Vehicle Types}

The monitored enforcement vehicles consist of the types of vehicles identified in Figure 26.

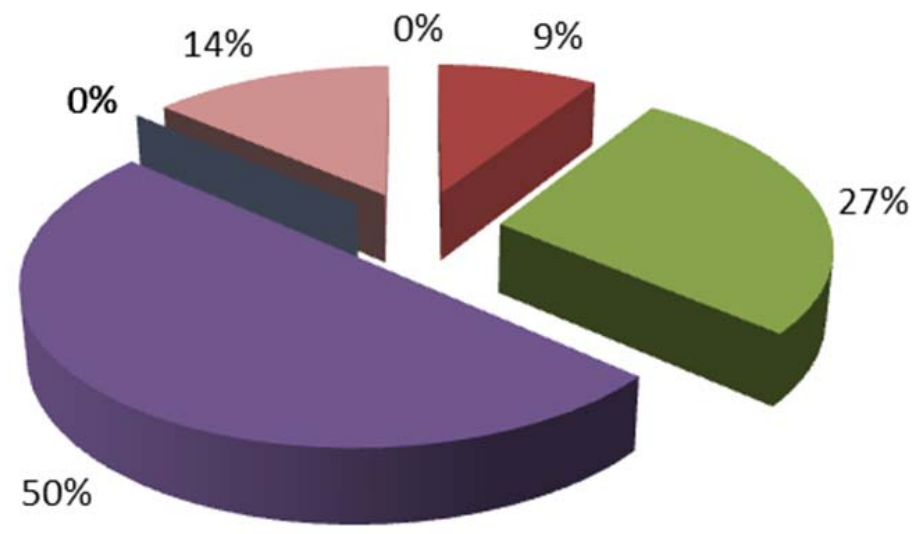

Sedan - Compact

- Sedan - Midsize

Sedan - Large

SUV

Minivan

Van - Cargo

Van - Pass

Pickup

Figure 26. Monitored enforcement vehicle types.

The monitored enforcement vehicles were predominately SUVs and large sedans.

\subsection{Transport Vehicle Analysis}

\subsubsection{General Vehicle Information}

Transport vehicles are typically light-duty trucks and vans utilized to carry cargo. Table 10identifies the three vehicles monitored.

Incorporation of BEVs and/or PHEVs into the transport mission is a definite possibility. Transport vehicles used for shorter trips or outings qualify for BEV or PHEV replacement, while other transport vehicle activities that are associated with longer trips may require PHEV capabilities. 


\subsubsection{Summary for Transport Vehicles}

This section aggregates data for all transport vehicles that were monitored. Table 15 summarizes transport travel during the study period for those days when the vehicle was driven. The vehicles were driven 638 miles, logged 65 hours, and idled for 14 hours during the study period.

Table 15. Transport vehicles travel summary.

\begin{tabular}{lcccc}
\hline \multicolumn{4}{c}{ Transport Vehicles Travel Summary } & \\
& $\begin{array}{c}\text { Per Day } \\
\text { Average/Peak }\end{array}$ & $\begin{array}{c}\text { Per Outing } \\
\text { Average/Peak }\end{array}$ & $\begin{array}{c}\text { Per Trip } \\
\text { Average/Peak }\end{array}$ & Total \\
\hline Travel Distance (Miles) & $8.8 / 25.5$ & $3.6 / 23.4$ & $1.3 / 14.5$ & 638 \\
Travel Time (Minutes) & $51.8 / 158.0$ & $21.6 / 147.0$ & $7.6 / 135.0$ & 3,893 \\
Idle Time (Minutes) & $11.5 / \mathrm{NA}$ & $7.1 / \mathrm{NA}$ & $2.7 / \mathrm{NA}$ & 824 \\
\hline
\end{tabular}

\subsubsection{Transport Vehicles Daily Summary}

When driven, the average travel distance per day for transport vehicles was 8.8 miles. The peak travel day was 25.5 miles. The outing information reveals similar information. Because only three vehicles were monitored, the detailed analysis provided for the other mission vehicles is unnecessary. For these three vehicles, BEVs were recommended as replacement vehicles.

The three vehicles studied included one SUV, one pickup truck, and one minivan. All have PEV replacement types available. Frequently, the full fleet of transport vehicles will include medium and heavy-duty trucks and cargo vans. While increasing numbers of medium-duty vehicles and vans in PEV types are becoming available, vehicles of the types studied are available. Forty-five vehicles of these types were reported in the full fleets of the agencies studied. Of these, 34 BEVs and 11 PHEVs were suggested as replacements.

\subsection{Balance of Fleet Missions}

Vehicle missions not studied include low-speed vehicles, buses, and specialty vehicles. Low-speed vehicles have received significant attention in federal fleets, with many agencies already using electric drive low-speed vehicles. Electric buses and specialty vehicles typically have unique battery and charging requirements. They were not included in this study, although electric drive vehicles are being developed and delivered.

\subsection{Fleet Mission Summary}

Table 16 provides a summary of the mission analysis conducted. Because greater benefit in fuel cost reduction and GHG emissions reduction occurs with BEVs, the intent is to increase the percentage of BEVs where possible. In Table 16, the most conservative approach was shown as the maximum percentage of BEVs that meet all average and maximum daily travel without additional charging or fleet management attention. A more considered approach would allow more BEVs to be introduced into the fleet. The percentages for the monitored vehicles and the related full agencies' fleets are also shown.

Table 16. All mission vehicle summary of possible PEV replacement.

\begin{tabular}{lcccccc} 
& \multicolumn{2}{c}{ Most Conservative } & \multicolumn{2}{c}{ Monitored Vehicles } & \multicolumn{2}{c}{ Full Fleet } \\
\multicolumn{1}{c}{ Mission } & BEVs & PHEVs & BEVs & PHEVs & BEVs & PHEVs \\
\hline Pool & $26 \%$ & $74 \%$ & $52 \%$ & $48 \%$ & $44 \%$ & $56 \%$ \\
Support & $41 \%$ & $59 \%$ & $52 \%$ & $48 \%$ & $51 \%$ & $49 \%$ \\
Enforcement & $23 \%$ & $77 \%$ & $18 \%$ & $81 \%$ & $39 \%$ & $61 \%$ \\
All Missions & NA & NA & $48 \%$ & $52 \%$ & $48 \%$ & $52 \%$ \\
\hline
\end{tabular}


Fleet managers should consider introduction of PEVs into their pool, support, and enforcement fleets. Their daily operation is anticipated to be similar to those monitored, resulting in BEVs being easily incorporated into daily operation. As experience grows with BEVs, the fleet manager may find the need to increase the percentage of BEVs in his/her fleets.

\section{GREENHOUSE GAS EMISSIONS AVOIDED AND FUEL COST REDUCTION ANALYSIS}

PEV substitutions for existing conventional vehicles avoid GHG emissions and reduce fuel costs. The GHG emissions avoided occur due to the difference in emissions associated with power plant electricity generation versus fuel combustion that occurs in the engine of a conventional vehicle. This analysis does not account for life-cycle emissions that occur outside of electricity generation and fuel combustion phases (i.e., materials and resource extraction, production supply chains, and decommissioning are not accounted for). These phases are beyond the scope of this report due to the significant effort required to conduct an accurate environmental life-cycle assessment for a transportation system in a very specific setting. The analysis used is known as a "tank-to-wheel" analysis rather than a "well-to-wheel" analysis that would include the aforementioned phases. However, it should be noted that transmission losses in electricity transport have been neglected. Cost reduction also occurs because the cost of electricity is comparable to the cost of gasoline on a unit of energy basis, but electric motors are more efficient than ICEs. Agencies provided information related to the current average annual mileage per vehicle. These were compared to the mileages measured during the study to identify the source of fuel consumption estimates for the study vehicles and to use the PEV replacement scenario to estimate a reduction in GHG emissions and fuel costs.

In order to perform the analysis, EPA fuel economy ratings were used. ${ }^{28}$ Table 17 provides these ratings. Ratings for the PHEVs include CD operation. Because these data are estimates, assumptions include the following:

1. PHEVs operated in CD mode only for the percentage of travel less than 40 miles per day. This was reasonable for most daily operations. This was conservative because additional charge time existed between most outings. It was also conservative because the replacement PEV typically will have greater fuel economy when operating in CS mode than the original ICE vehicle. BEVs operated in electric mode for $100 \%$ of travel.

2. Energy consumption for the Mitsubishi Outlander was assigned the same value as the RAV4 EV. The Via Motors pickup and van models and the Nissan eNV200 energy consumption values were estimated because EPA has not yet created ratings for these vehicles.

3. Table 17suggests PEVs for replacing existing monitored vehicles. Other models exist, including aftermarket modifications. See Section 4.4 for vehicle availability.

4. Annual miles were calculated from the actual miles identified by the agency, where available. Miles in $\mathrm{CD}$ mode were the annual miles times percent of daily travel less than 40 miles for PHEV replacement and full annual miles for BEV replacement.

Calculations provided for the agencies' GHG emissions and fuel savings included both a total U.S. perspective and perspective for the agencies' local areas. The electricity generation mix of power plants for the total United States is different from the local mix of generation in the agencies' areas. Likewise, the national average cost for petroleum fuel is different from the local cost for fuel. The analysis includes both approaches in order to allow for local evaluation and to provide the potential benefit for fleet vehicles in other locations of the United States that may be of interest. This final report summarizing results from all sites studied uses the national figures only.

\footnotetext{
${ }^{28}$ http://www.fueleconomy.gov/feg/Find.do?action=sbs\&id=33558 [accessed February 2, 2014].
} 
Table 17. PEV substitutions for current vehicles.

\begin{tabular}{|c|c|c|c|}
\hline Vehicle Class & Current Vehicle Example & Replacement PHEV & Replacement BEV \\
\hline $\begin{array}{l}\text { Sedan - } \\
\text { Compact/Subcompact }\end{array}$ & 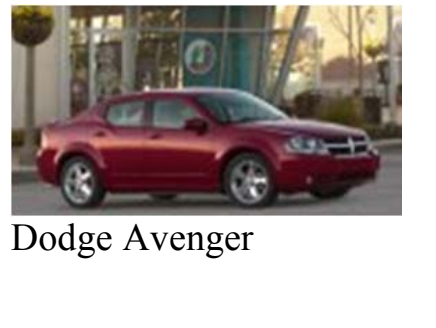 & $\begin{array}{l}\text { Chevrolet Volt } \\
350 \mathrm{Wh} / \mathrm{mi}\end{array}$ & $\begin{array}{l}\text { Ford Focus Electric } \\
310 \mathrm{Wh} / \mathrm{mi}\end{array}$ \\
\hline Sedan - Midsize/Large & Chevrolet Impala & $\begin{array}{l}\text { Ford Fusion Energi* } \\
370 \mathrm{Wh} / \mathrm{mi}\end{array}$ & $\begin{array}{l}\text { Nissan Leaf } \\
300 \mathrm{Wh} / \mathrm{mi}\end{array}$ \\
\hline SUV and Minivan & Chevrolet Tahoe & $\begin{array}{l}\text { Mitsubishi Outlander } \\
\text { PHEV } 440 \mathrm{Wh} / \mathrm{mi}\end{array}$ & $\begin{array}{l}\text { Kia Soul Electic } \\
320 \mathrm{Wh} / \mathrm{mi}\end{array}$ \\
\hline Pickup Truck & Chevrolet Colorado & $\begin{array}{l}\text { Via Motors VTRUX } \\
475 \mathrm{Wh} / \mathrm{mi}\end{array}$ & $\begin{array}{l}\text { Nissan eNV200 } \\
400 \mathrm{Wh} / \mathrm{mi}\end{array}$ \\
\hline $\begin{array}{l}\text { Pickup Truck } \\
\text { (alternate) }\end{array}$ & Ford F-150 & $\begin{array}{l}\text { Mitsubishi Outlander } \\
\text { PHEV } 440 \mathrm{Wh} / \mathrm{mi}\end{array}$ & $\begin{array}{l}\text { Kia Soul Electric } \\
320 \mathrm{Wh} / \mathrm{mi}\end{array}$ \\
\hline Cargo Van & Chevrolet Express Van & $\begin{array}{l}\text { Via VTRUX Van } \\
475 \mathrm{Wh} / \mathrm{mi}\end{array}$ & $\begin{array}{l}\text { Nissan eNV200 } \\
400 \mathrm{Wh} / \mathrm{mi}\end{array}$ \\
\hline Passenger Van & Ford E-350 & $\begin{array}{l}\text { Via VTRUX Van } \\
475 \mathrm{Wh} / \mathrm{mi}\end{array}$ & 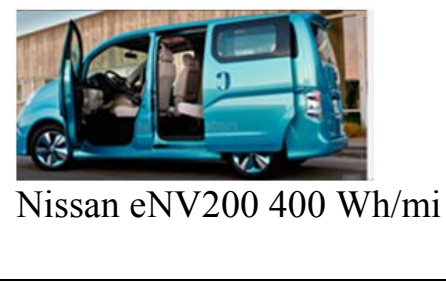 \\
\hline
\end{tabular}

*Note CD range for Fusion Energi is approximately 20 miles. 
For the GHG emissions avoided portion of the analysis, the GHG emissions (in pounds of carbon dioxide equivalent, which also accounts for other GHGs such as methane and nitrous oxide, $\mathrm{lb}-\mathrm{CO}_{2} e$ ) from combustion of gasoline is $20.1 \mathrm{lb}-\mathrm{CO}_{2} \mathrm{e} /$ gallon. ${ }^{29}$ The United States averages for GHG emissions for the production of electricity is $1.53 \mathrm{lb}-\mathrm{CO}_{2} \mathrm{e} / \mathrm{kWh}^{30}$ In the agencies reports, the local generation mix determined the GHG emissions used in the local calculations.

GHG emissions avoided are the GHG emitted by the current vehicle (total annual gallons gasoline $\times$ GHG emissions/gallon) minus the annual GHG emitted by the replacement PEV (total annual $\mathrm{kWh} \times \mathrm{GHG}$ emissions/kWh). For the PHEVs, the percentages of outings less than 40 miles were counted for the annual miles saved in CD mode, with the balance of the miles accounted as fueled with gasoline.

For the cost-avoided piece of the analysis, fuel cost assumptions were based on local and national averages at the time of the report. They ranged from $\$ 2.42$ to $\$ 3.75 /$ gallon with an average of $\$ 3.33 /$ gallon of gasoline for the United States. ${ }^{31}$ Electrical cost used was $0.0984 \$ / \mathrm{kWh}$ for the United States. ${ }^{32}$ Therefore, fuel costs savings were the current vehicle's calculated annual gasoline cost (total annual gallons gasoline $\times$ cost/gallon) minus the electricity cost (total annual $\mathrm{kWh} \times \operatorname{cost} / \mathrm{kWh}$ ) of the replacement PEV traveling the same distance.

The miles calculated for CD mode yield estimates for yearly GHG emissions avoided and fuel cost reductions. The results of this analysis demonstrate that the substitution of a conventional ICE vehicle with a PEV can reduce GHG emissions and fuel costs dramatically. Table 18 shows the savings in fuel and GHG emissions using national figures by federal agency and includes the percentage reductions for ease of comparison, assuming the monitored vehicles are replaced with the appropriate PEV.

Table 18. GHG emissions avoidance and fuel cost reduction for monitored vehicles.

\begin{tabular}{lccccc}
\multicolumn{1}{c}{ Agency } & $\begin{array}{c}\text { Vehicles } \\
\text { Replaced }\end{array}$ & $\begin{array}{c}\text { Annual } \mathrm{CO}_{2} \mathrm{e} \\
\text { Avoided } \\
(\text { lb-CO }\end{array}$ & $\begin{array}{c}\text { Percent } \\
\text { Reduction }\end{array}$ & $\begin{array}{c}\text { Annual Fuel Cost } \\
\text { Reduction }(\$)\end{array}$ & $\begin{array}{c}\text { Percent } \\
\text { Reduction }\end{array}$ \\
\hline GGNRA & 14 & 56,114 & $45 \%$ & $\$ 17,515$ & $69 \%$ \\
FVNHS & 2 & 5,869 & $40 \%$ & $\$ 1,772$ & $70 \%$ \\
GCNP & 11 & 43,600 & $47 \%$ & $\$ 12,455$ & $75 \%$ \\
RMNP & 6 & 12,570 & $49 \%$ & $\$ 3,864$ & $84 \%$ \\
SLBE & 14 & 29,805 & $43 \%$ & $\$ 9,428$ & $78 \%$ \\
CTNF & 10 & 33,205 & $54 \%$ & $\$ 10,795$ & $84 \%$ \\
WSTF & 10 & 40,258 & $47 \%$ & $\$ 11,177$ & $80 \%$ \\
GRC & 10 & 14,521 & $32 \%$ & $\$ 5,761$ & $75 \%$ \\
SSC & 12 & 21,216 & $40 \%$ & $\$ 6,761$ & $77 \%$ \\
USCG & 10 & 5,109 & $10 \%$ & $\$ 5,417$ & $68 \%$ \\
ASPR & 5 & 13,285 & $51 \%$ & $\$ 3,009$ & $79 \%$ \\
VA-Br & 6 & 11,502 & $31 \%$ & $\$ 4,221$ & $72 \%$ \\
VA-Man & 7 & 11,398 & $24 \%$ & $\$ 5,192$ & $69 \%$ \\
NIH & 20 & 47,910 & $43 \%$ & $\$ 14,394$ & $78 \%$ \\
INL & 12 & 22,139 & $40 \%$ & $\$ 4,539$ & $68 \%$ \\
Total & $\mathbf{1 4 9}$ & $\mathbf{3 6 8 , 5 0 1}$ & - & $\$ 116,300$ & - \\
Avg/Vehicle & - & 2,473 & - & $\$ 781$ & - \\
Avg/Agency & 10 & 24,567 & $40 \%$ & $\$ 7,753$ & $75 \%$ \\
\hline
\end{tabular}

\footnotetext{
${ }^{29}$ http://www.theevproject.com/cms-assets/documents/106077-891082.ghg.pdf.

30 ibid.

${ }^{31} \mathrm{http}: / /$ www.eia.gov/dnav/pet/pet_pri_gnd_dcus_sco_w.htm [accessed July 25 2014].

${ }^{32} \mathrm{http}: / /$ www.eia.gov/electricity/state/ [accessed July 25, 2014].
} 
Table 18 shows the high potential benefit in reduction of GHG emissions and fuel costs. The benefits derived from replacement PEVs are highly dependent on existing ICE vehicle fuel economy and usage characteristics.

The agency reports also projected savings per agency should the agency replace available ICE vehicles with PEVs. Table 19 summarizes the avoided GHG and fuel cost savings should these replacements occur. The size of the total fleet for some agencies was not available. The table also shows the percentage reduction in GHG emissions and fuel costs for ease of comparison.

Table 19. Extrapolated GHG emissions avoided and fuel cost savings for the entire fleets.

\begin{tabular}{lccccc}
\hline Agency & $\begin{array}{c}\text { Fleet } \\
\text { Replacement } \\
\text { Size }\end{array}$ & $\begin{array}{c}\text { Annual } \mathrm{CO}_{2} \mathrm{e} \text { Avoided } \\
\left(\mathrm{lb}-\mathrm{CO}_{2} \mathrm{e} / \text { year }\right)\end{array}$ & $\begin{array}{c}\text { Percent } \\
\text { Reduction }\end{array}$ & $\begin{array}{c}\text { Annual Fuel Cost } \\
\text { Reduction }(\$)\end{array}$ & $\begin{array}{c}\text { Percent } \\
\text { Reduction }\end{array}$ \\
\hline GGNRA & 105 & 338,313 & $44 \%$ & $\$ 107,490$ & $69 \%$ \\
FVNHS & $\mathrm{NA}$ & - & - & - & - \\
GCNP & 218 & $1,454,610$ & $69 \%$ & $\$ 296,044$ & $80 \%$ \\
RMNP & 164 & 664,573 & $59 \%$ & $\$ 175,128$ & $84 \%$ \\
SLBE & 52 & 108,213 & $41 \%$ & $\$ 34,941$ & $78 \%$ \\
CTNF & 66 & 203,129 & $45 \%$ & $\$ 69,603$ & $78 \%$ \\
WSTF & 105 & 404,321 & $48 \%$ & $\$ 115,657$ & $80 \%$ \\
GRC & 20 & 32,881 & $35 \%$ & $\$ 12,298$ & $76 \%$ \\
SSC & $\mathrm{NA}$ & - & - & - & - \\
USCG & $\mathrm{NA}$ & - & - & - & - \\
ASPR & $\mathrm{NA}$ & - & - & - & - \\
VA-Br & 23 & 36,522 & $27 \%$ & $\$ 14,913$ & $71 \%$ \\
VA-Man & 59 & 122,155 & $45 \%$ & $\$ 169,629$ & $79 \%$ \\
NIH & 264 & 586,078 & $42 \%$ & $\$ 178,126$ & $69 \%$ \\
INL & 378 & 893,096 & & $\$ 1,229,191$ & \\
Total & 1,454 & $4,843,891$ & & & \\
\hline
\end{tabular}

Tables 18 and 19 illustrate the increasing benefits of federal fleet adoption of PEVs.

\section{OBSERVATIONS}

Intertek appreciates the opportunity to present the results of this study. Observations were provided to each of the agencies in their individual reports. Overall observations are presented as follows:

\section{Observation \#1:}

Replacement PEVs: Many agencies are not fully informed about the current availability of potential replacement PEVs. Certainly, PEVs of the exact body type of the current fleet may not be available; however, more vehicle manufacturers and after-market companies are responding to the growing PEV market with new vehicles of a wider range of body types. GSA currently only lists Ford and Chevrolet sedans for PHEVs, but, as seen in Section 4.4, other vehicles and options are available. For example, Charged Electric Vehicle Magazine recently reported that, "Los Angeles Air Force Base has replaced its entire general-purpose fleet with plug-in vehicles. The 42-vehicle fleet includes 13 Nissan Leafs, five Ford pick-up trucks with EVAOS PHEV kits, nine VIA Motors VTRUX vans, four Electric Vehicle International medium-duty trucks, and one Phoenix Motorcars 12-passenger bus. ${ }^{, 33}$ Replacement PEVs are available to meet vehicle mission requirements.

\footnotetext{
${ }^{33}$ Charged Electric Vehicle Magazine, November/December 2014, p. 41.
} 


\section{Observation \#2:}

Fleet Vehicle Management: Management of fleets containing PEVs will be more challenging than ICE vehicles. Fueling is quite different and fueling stations (i.e., EVSE) are not as plentiful outside the agency's facility. However, the analysis conducted in this study shows that most vehicles rarely leave the facility and sufficient time is available for overnight charging to meet daily travel needs. For a mix of BEVs and PHEVs, the fleet manager will need to understand the desired use of the vehicle to appropriately assign a BEV so it will not exceed its range prior to its return. As with all technologies, as the manager's level of experience and the user's level of experience increase, comfort in the selection of vehicles will also increase.

\section{Observation \#3:}

Fuel Cost Savings: Projected savings from use of PEVs were conservatively derived and are significant. The projected annual mileage for an average monitored vehicle is 5,341 miles. The average fuel savings per vehicle is $\$ 781$, providing an average of $75 \%$ reduction in fuel costs. These annual savings may be used to offset differential purchase cost or the cost of EVSE installation.

\section{Observation \#4:}

GHG Reduction: Use of PEVs provides the opportunity for a significant reduction in the emissions of GHGs. Replacing $149 \mathrm{ICE}$ vehicles with the appropriate PEVs provides a reduction of $368,000 \mathrm{lb}-\mathrm{CO}_{2} \mathrm{e}$ per year, which is more than 1 ton per vehicle per year. This directly supports the directives identified in Section 1.

The support of the individual agencies in providing information and supporting the onsite efforts required for data logging and reporting is appreciated. Hopefully the individual agency reports are helpful in expanding the use of PEVs for federal agencies. 